\title{
Two-Dimensional Cochlear Micromechanics Measured In Vivo Demonstrate Radial Tuning within the Mouse Organ of Corti
}

\author{
Hee Yoon Lee, ${ }^{1}$ Patrick D. Raphael, ${ }^{2}{ }^{\oplus}$ Anping Xia, ${ }^{2}$ Jinkyung Kim, ${ }^{2}$ - Nicolas Grillet, ${ }^{2}$ Brian E. Applegate, ${ }^{3}$ \\ ㄱA Audrey K. Ellerbee Bowden, ${ }^{1}$ and $\odot$ John S. Oghalai ${ }^{2}$ \\ ${ }^{1}$ E.L. Ginzton Laboratory and Department of Electrical Engineering, Stanford University, Stanford, California 94305, ${ }^{2}$ Department of Otolaryngology-Head \\ and Neck Surgery, Stanford University, Stanford, California 94305, and ${ }^{3}$ Department of Biomedical Engineering, Texas A\&M University, College Station, \\ Texas 77843
}

The exquisite sensitivity and frequency discrimination of mammalian hearing underlie the ability to understand complex speech in noise. This requires force generation by cochlear outer hair cells ( $\mathrm{OHCs})$ to amplify the basilar membrane traveling wave; however, it is unclear how amplification is achieved with sharp frequency tuning. Here we investigated the origin of tuning by measuring sound-induced 2-D vibrations within the mouse organ of Corti in vivo. Our goal was to determine the transfer function relating the radial shear between the structures that deflect the $\mathrm{OHC}$ bundle, the tectorial membrane and reticular lamina, to the transverse motion of the basilar membrane. We found that, after normalizing their responses to the vibration of the basilar membrane, the radial vibrations of the tectorial membrane and reticular lamina were tuned. The radial tuning peaked at a higher frequency than transverse basilar membrane tuning in the passive, postmortem condition. The radial tuning was similar in dead mice, indicating that this reflected passive, not active, mechanics. These findings were exaggerated in Tecta ${ }^{\mathrm{C} 1509 \mathrm{G} / \mathrm{C} 1509 \mathrm{G}}$ mice, where the tectorial membrane is detached from $\mathrm{OHC}$ stereocilia, arguing that the tuning of radial vibrations within the hair cell epithelium is distinct from tectorial membrane tuning. Together, these results reveal a passive, frequency-dependent contribution to cochlear filtering that is independent of basilar membrane filtering. These data argue that passive mechanics within the organ of Corti sharpen frequency selectivity by defining which OHCs enhance the vibration of the basilar membrane, thereby tuning the gain of cochlear amplification.

Key words: auditory system; cochlea; frequency discrimination; hearing; mechanics; transduction

\section{Significance Statement}

Outer hair cells amplify the traveling wave within the mammalian cochlea. The resultant gain and frequency sharpening are necessary for speech discrimination, particularly in the presence of background noise. Here we measured the 2-D motion of the organ of Corti in mice and found that the structures that stimulate the outer hair cell stereocilia, the tectorial membrane and reticular lamina, were sharply tuned in the radial direction. Radial tuning was similar in dead mice and in mice lacking a tectorial membrane. This suggests that radial tuning comes from passive mechanics within the hair cell epithelium, and that these mechanics, at least in part, may tune the gain of cochlear amplification.

\section{Introduction}

A sound pressure wave propagates up the length of the cochlea in the form of a traveling wave (von Békésy, 1960). The location of the peak of the traveling wave varies according to the tonotopic

Received April 6, 2016; revised May 18, 2016; accepted June 7, 2016.

Author contributions: H.Y.L., P.D.R., A.X., J.K., N.G., B.E.A., A.K.E.B., and J.S.O. designed research; H.Y.L., P.D.R., A.X., J.K., N.G., and J.S.O. performed research;H.Y.L., P.D.R., A.X., J.K., N.G., B.E.A., A.K.E.B., and J.S.O. analyzed data; H.Y.L., N.G., B.E.A., A.K.E.B., and J.S.O. wrote the paper.

This work was supported by National Institutes of Health, National Institute on Deafness and Other Communication Disorders Grants DC014450, DC013774, and DC010363, the Stanford Crack the Neural Code Seed Grant map defined by passive mechanical gradients in stiffness and mass. The cochlear base is tuned to high frequencies and the apex is tuned to low frequencies. Active processes within outer hair cells (OHCs) associated with somatic electromotility (Brownell et

\footnotetext{
Program, and a Stanford Nano Shared Facilities Seed Grant. We thank Drs. Charles Steele, Sunil Puria, and Tony Ricci for helpful discussions; and Chris Gralapp for artwork.

The authors declare no competing financial interests.

Correspondence should be addressed to Dr. John S. Oghalai, Department of Otolaryngology-Head and Neck Surgery, 801 Welch Road, Stanford, CA 94305-5739. E-mail: joghalai@stanford.edu. DOl:10.1523/JNEUROSCI.1157-16.2016

Copyright $\odot 2016$ the authors $\quad 0270-6474 / 16 / 368160-14 \$ 15.00 / 0$
} 

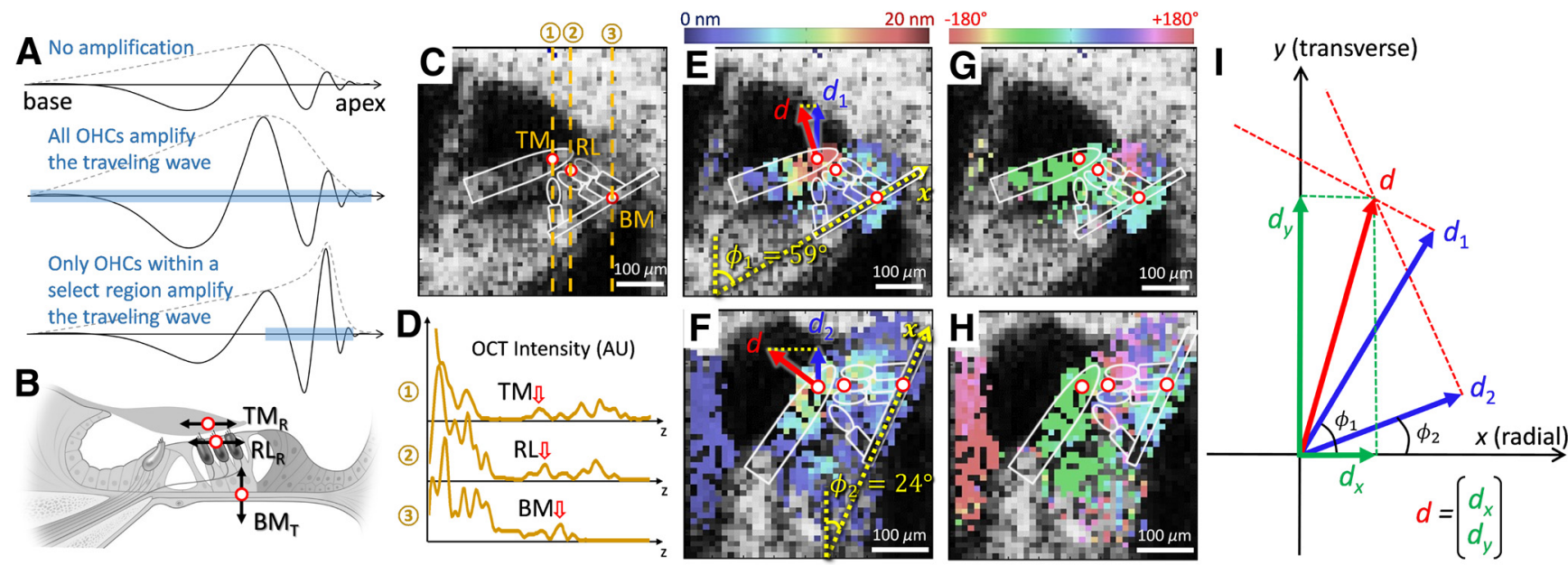

Figure 1. A, Schematic of traveling waves along the cochlea. The displacement of the basilar membrane in the transverse direction at one point in time (solid lines) and the peak envelope (dotted lines) in response to a pure tone stimulus are shown. The postmortem response (top) stems from the passive mechanics of the basilar membrane, and there is no amplification. If the forces of amplification delivered by every $\mathrm{OHC}$ were proportional to the displacement of the basilar membrane under it (i.e., equal gain along the length of the cochlea), the traveling wave would essentially be a magnified version of the postmortem response (middle). In contrast, the normal response in a living cochlea exhibits sharpened tuning with a shifted peak location (bottom). This is consistent with the forces of amplification being delivered only over a localized region of the basilar membrane. $\boldsymbol{B}$, Schematic cross-section of the organ of Corti. We focused our analyses on transverse motion of the basilar membrane $\left(B M_{T}\right)$, the radial motion of the reticular lamina $\left(R L_{R}\right)$, and the radial motion of the tectorial membrane $\left(T M_{R}\right)$. C, Cross-sectional OCT anatomic image $(B$-scan) of a mouse cochlea in vivo. The optical axis through each measurement point is shown (dotted lines). $\boldsymbol{D}$, Plots of the image intensity versus depth (A-scan) for the three measurement locations. The locations we measured could be identified as peaks in the tracings. $\mathbf{E}-\boldsymbol{H}$, Cross-sectional $0 \mathrm{CT}$ images of a mouse cochlea taken at two different angles relative to the optical axis $\left(\phi_{1}, \phi_{2}\right)$. The vibratory magnitude (left images) and phase (right images) to a $10 \mathrm{kHz}, 20 \mathrm{~dB} \mathrm{SPL}$ pure tone are pseudocolored and superimposed upon the anatomic image. The actual 2-D motion of any structure in the image could be calculated by measuring the projected motion from these two images. In this example, the $\mathrm{BM}_{\mathrm{T}}$ (red arrows) is shown projected onto the optical path of the $0 \mathrm{OCT}$ laser (blue arrows). I, Calculation of vibrations in 2-D from two different measurement angles. The $x$ - and $y$-axes represent the radial and transverse directions, respectively. The measured vibrations $\left(d_{1}\right.$ and $\left.d_{2}\right)$ were in the direction of the two different optical paths. Their projections were used to calculate the actual 2-D motion of the point, $d$, in the radial and transverse directions, $d_{x}$ and $d_{y}$ ( $g r e e n$ arrows).

al., 1985) and/or stereociliary bundle motility (Nin et al., 2012) generate force to amplify and sharpen the tuning of the traveling wave, a process termed cochlear amplification (Davis, 1983). Thus, sound stimuli produce larger vibratory responses and sharper frequency tuning in living compared with dead animals (Rhode, 1971; Nuttall and Dolan, 1996; Robles and Ruggero, 2001). Eliminating the power to drive OHC motility by removing the endocochlear potential (Ruggero and Rich, 1991), removing OHC stimulation by removing the tectorial membrane (TM) (Legan et al., 2000), or inactivating the OHC motor protein prestin (Dallos et al., 2008) are all known to reduce both the gain and the sharpness of frequency tuning in the basilar membrane (BM) vibratory response. These data indicate that $\mathrm{OHCs}$ are needed for both amplification and sharp frequency tuning.

However, the concept that OHCs simply amplify the broadly tuned traveling wave cannot alone explain the exquisite sharpness of BM tuning (Evans, 1972; Allen and Fahey, 1992). If each $\mathrm{OHC}$ along the length of the cochlea provided equal gain, the tuning of the traveling wave would not be sharp enough to match what has been measured in BM motion (Fig. 1A). Instead, an additional filtering step within the organ of Corti has been proposed to account for the apparent frequency-selectivity of OHC amplification (Evans and Klinke, 1982; Markin and Hudspeth, 1995). According to this theory, additional filtering selectively tunes $\mathrm{OHC}$ stimulation, force production, and/or the impedance of the organ of Corti, so that the traveling wave is amplified only over a short region. Various components have been suggested to provide this additional filtering, including the TM (Hubbard, 1993; Gummer et al., 1996; Russell et al., 2007) fluid within the tunnel of Corti (Karavitaki and Mountain, 2007a), the Deiters' cell phalangeal processes (Geisler and Sang, 1995; Yoon et al., 2011), the stereociliary bundle (Fettiplace, 2006; Peng and Ricci,
2011; Hudspeth, 2014), and OHC electromotility (Neely and Kim, 1986; Mountain and Hubbard, 1994; Weitzel et al., 2003; Song and Santos-Sacchi, 2013).

In support of the concept of additional filtering within the organ of Corti, phase shifts in the vibration of the reticular lamina (RL) and in the electric field potential generated by hair cell transduction have been found near the frequency of maximal BM vibration to low-intensity stimuli (termed the characteristic frequency [CF]) (Dong and Olson, 2013; Ramamoorthy et al., 2014). Similarly, we found that the region of the organ of Corti containing the Hensen, Boettcher, and Claudius cells demonstrated a sharply tuned phase change in its vibratory response near the CF (Gao et al., 2014). Surprisingly, this phase change was present not only in control mice, but also in dead mice and in mutant mice that do not have cochlear amplification, suggesting that the filtering is passive.

If the mechanics of the organ of Corti produce additional filtering to sharpen tuning, this filtering may be represented in the frequency response of the OHC stereociliary bundle, which would then amplify the tuned stimulus. However, because hair cell stereocilia are stimulated by radial shear, measurements of radial motion are needed to test this hypothesis (Fig. 1B). Therefore, we measured the vibratory response of the organ of Corti in 2 -D to determine the transverse (up-and-down) and radial (sideto-side) vectors of motion in live and dead mice. We determined the frequency response of the transfer function relating the shear between the structures that deflect the OHC bundle, the TM and $\mathrm{RL}$, to the transverse motion of the $\mathrm{BM}\left(\mathrm{BM}_{\mathrm{T}}\right)$.

\section{Materials and Methods}

Mouse preparation. The study protocol was approved by the Stanford Institutional Animal Care and Use Committee. P28-P42 CBA/CaJ mice and Tecta ${ }^{\mathrm{C} 1509 \mathrm{G} / \mathrm{C} 1509 \mathrm{G}}$ mice of either sex were used (stock \#000654 and 
10826, The Jackson Laboratory). Each mouse was anesthetized with ketamine/xylazine, and its left middle ear bulla was surgically opened to access the cochlea without disturbing the otic capsule bone. We recorded from a region of the cochlear apex approximately a half-turn down from the apical end. After performing all the desired experiments in the living mouse, the animal was killed by anesthesia overdose so as not to move the head. Further measurements were made postmortem. Finally, vibration measurements were made from the middle ear ossicular chain to define the magnitude and phase of the sound entering the cochlea.

Volumetric optical coherence tomography vibrometry (VOCTV). Vibrations of the organ of Corti were measured using VOCTV. Our VOCTV system is custom-built and has been described previously (Lee et al., 2015). Briefly, it is composed of a broadband swept-source with a center wavelength of $1300 \mathrm{~nm}$ and $200 \mathrm{kHz}$ sweep rate (MEMS-VCSEL, Thorlabs), a dual-balanced photodetector (WL-BPD600MA, Wieserlabs), and a digitizer (NI-5761, National Instruments). An adaptor attached to the bottom of a dissecting microscope (Stemi-2000, Zeiss) scanned the beam in both the $x$ and $y$ directions. For all experiments, the power on the sample was $16 \mathrm{~mW}$. Sound stimuli were synthesized in software and output by a speaker (MDR EX37B, Sony) that was inserted into ear canal. We calibrated the stimuli using a probe-tip microphone in the ear bar as previously described (Oghalai, 2004; Xia et al., 2010, 2013). We presented pure tones from 2 to $13 \mathrm{kHz}$ in frequency steps of $0.5 \mathrm{kHz}$ at intensities from 10 to $80 \mathrm{~dB}$ SPL in $10 \mathrm{~dB}$ steps. The duration of the sound stimulus ranged from 50 to $200 \mathrm{~ms}$, with longer stimuli used for less intense stimuli to achieve a lower noise floor.

At any given $x-y$ location of the scan mirror, the vibratory data from all pixels along the optical path of the laser (comprising different structures in depth) were collected and analyzed simultaneously. We underfilled a $75 \mathrm{~mm}$ focal length objective lens to focus a collimated laser beam with a $1 / \mathrm{e}^{2}$ diameter of $6.7 \mathrm{~mm}$, giving an effective numerical aperture (NA) of 0.044 . In air this gives a $1 / \mathrm{e}^{2}$ diameter spot size of $18.7 \mu \mathrm{m}$. Because the laser beam has a Gaussian profile, we use the FWHM diameter of 10.9 $\mu \mathrm{m}$ as a better indication of imaging resolution. Therefore, in water, which has a refractive index of $\sim 1.3$ at $1300 \mathrm{~nm}$, the theoretical lateral imaging resolution is $8.4 \mu \mathrm{m}$. We have measured the lateral resolution of our VOCTV system and found it to be reasonably close to this at $9.8 \mu \mathrm{m}$ (Lee et al., 2015). With such a low NA objective, the axial resolution is set by the bandwidth of the laser source, and we measured this to be $11.4 \mu \mathrm{m}$ in water (Lee et al., 2015). The vibratory sensitivity of our system is within the picometer range, calibrated using a piezoelectric probe and a commercial laser Doppler Vibrometer (Applegate et al., 2011; Gao et al., 2013; Lee et al., 2015).

During the experiments, we selected points for study that had strong signal intensity on the image because these provided the lowest noise floor for the vibratory measurements. No averaging of adjacent points was performed. To minimize the potential for phase corruption, where the point spread functions overlap and vibrations from one point might affect the measurement at the other point (Ellerbee and Izatt, 2007), we only studied measurement points that were at least $30 \mu \mathrm{m}$ apart and in which the measurement point had an intensity that was a local maxima. Furthermore, vibration data from any given voxel were not analyzed if the image intensity of that voxel was within 3 SDs of the noise floor of the background intensity measured in perilymph. Similarly, we did not analyze vibration data if the vibratory magnitude at the stimulus frequency was below a threshold set at the mean $+3 \mathrm{SD}$ of the vibratory noise floor measured at nearby frequencies.

Vibratory measurements. Most of our measurements were made at three locations: the BM, the RL, and the TM. The BM was measured in its mid-point, the RL was measured at the apical edge of the $\mathrm{OHC}$ region, and the TM was measured in the mid-portion of the region overlying the OHCs. We selected these measurement positions using three criteria. First, the anatomic image (termed a B-scan in the OCT literature) was used to provide an assessment of organ of Corti anatomy (Fig. 1C). Second, plots of the intensity versus depth along selected optical path of the three points (termed A-scans in the OCT literature) were used to identify peaks that corresponded to the structures of interest (Fig. $1 D$ ). Third, we presented acoustic stimuli and collected the vibratory magnitude and phase responses at every point in the image. Plotting these responses in pseudocolor superimposed upon the anatomic image demonstrated that these nearby structures had clearly different vibratory responses (Fig. $1 E-H$ ) and thus helped confirm our selected measurement points.

Vibratory measurements were made from the same cochlear location at two different angles. Example images taken from one mouse are shown in Figures $1 E, G$ and Figures $1 F, H$. This was done by rotating the head of the mouse while maintaining the plane of the cross-sectional image. We verified that the cochlear cross-section did not change in two ways. First, before measuring at either angle, we collected a volumetric series of images by scanning the beam in both the $x$ and $y$ directions. We viewed the image stack to verify that the angle of the organ of Corti cross-section we selected was not skewed. When necessary, the scan angle was rotated using our software to minimize the width of the scala media and achieve a perpendicular slice. This was done to guarantee that the cochlear crosssections we measured from were always perpendicular to the longitudinal axis of the cochlear duct. Second, after rotating the head, the vibratory phase of the basilar membrane at the characteristic frequency was checked to make sure it was the same as before the head was rotated. This was done to verify that we were at the same longitudinal location.

Even though we were careful to maintain the position of the speaker in the ear canal, changing the orientation of the head of the mouse could potentially affect the distance between the speaker and the tympanic membrane, producing a phase error. We calculated, however, that, even in a worst-case scenario where the speaker moved $1 \mathrm{~mm}$ in air, the phase error would only be $3 \%$ at $10 \mathrm{kHz}\left(\sim 11^{\circ}\right)$. Therefore, this potential issue has little impact on our interpretation of the data.

Reconstruction of 2-D motion. After measuring the motion of these locations with the animal rotated at two different angles, we then calculated the transverse and radial vectors of motion for each of these locations (Fig. 1I). A vibratory response with respect to the harmonic input sound stimulus is held in 3-D space; however, our study focuses on its projected motion in the cross-section of the cochlea, $d=\left(d_{x}, d_{y}\right)$, where $d$ is the 2-D displacement of the point being measured, $d_{x}$ and $d_{y}$ compose the radial and transverse orthogonal vectors of time-varying motion, respectively. However, because our system can only measure the onedimensional projected motion along the laser axis, at least two measurements at different laser angles ( $\phi_{1}$ and $\phi_{2}$ with respect to the radial axis) are required to reconstruct the 2-D motion. Therefore, we describe the two measured displacement vectors as $d_{i}=\left(a_{i} \cdot \cos \right.$ $\left(\omega t+\theta_{i}\right), a_{i} \cdot \sin \left(\omega t+\theta_{i}\right)$, where $a_{i}$ is the measured vibratory magnitude, $\theta_{i}$ is the measured vibratory phase, $\omega$ is the frequency in radians, $t$ is time, and $i=1$ or 2 to identify the measurement angle. Given these two measured arbitrary vectors of motion, we can reconstruct the 2-D motion of the point, $d(t)$, by solving for the intersection of two lines normal to the end of the vectors (Fig. 1I, red dotted lines) as follows:

$$
\begin{aligned}
d(t)= & \left(\begin{array}{c}
d_{x} \\
d_{y}
\end{array}\right) \\
& =\left[\begin{array}{c}
\frac{-1 / \sin \left(\phi_{1}\right)}{\cot \left(\phi_{2}\right)-\cot \left(\phi_{1}\right)} d_{1}+\frac{1 / \sin \left(\phi_{2}\right)}{\cot \left(\phi_{2}\right)-\cot \left(\phi_{1}\right)} d_{2} \\
\frac{1 / \sin \left(\phi_{1}\right)}{1-\cot \left(\phi_{1}\right) / \cot \left(\phi_{2}\right)} d_{1}+\frac{1 / \sin \left(\phi_{2}\right)}{1-\cot \left(\phi_{2}\right) / \cot \left(\phi_{1}\right)} d_{2}
\end{array}\right] .
\end{aligned}
$$

The magnitude and phase of the radial $(x)$ and transverse $(y)$ vectors of the 2-D motion can be obtained by taking the absolute values and angles of the complex numbers in each coordinate (Fig. 1I, green arrows). As an example, if the two measurement angles were exactly the $x$ and $y$ axes, then the reconstructed 2-D motion would be $d=\left(d_{1}, d_{2}\right)$, which is the same as the output from Equation 1 when $\phi_{1}=0^{\circ}$ and $\phi_{2}=90^{\circ}$.

Practically, to perform these calculations, we first identified the basilar membrane from the anatomic image. Each of the images and its vibratory data were segmented visually by comparing the OCT images to twophoton images of the mouse cochlea at the same cochlear location (Soons et al., 2015). Transverse motion was defined as being perpendicular to the basilar membrane (the $y$ direction) and radial motion was defined as being parallel to the basilar membrane (the $x$ direction). The angle of the vibratory measurement was then determined as the angle of the basilar 

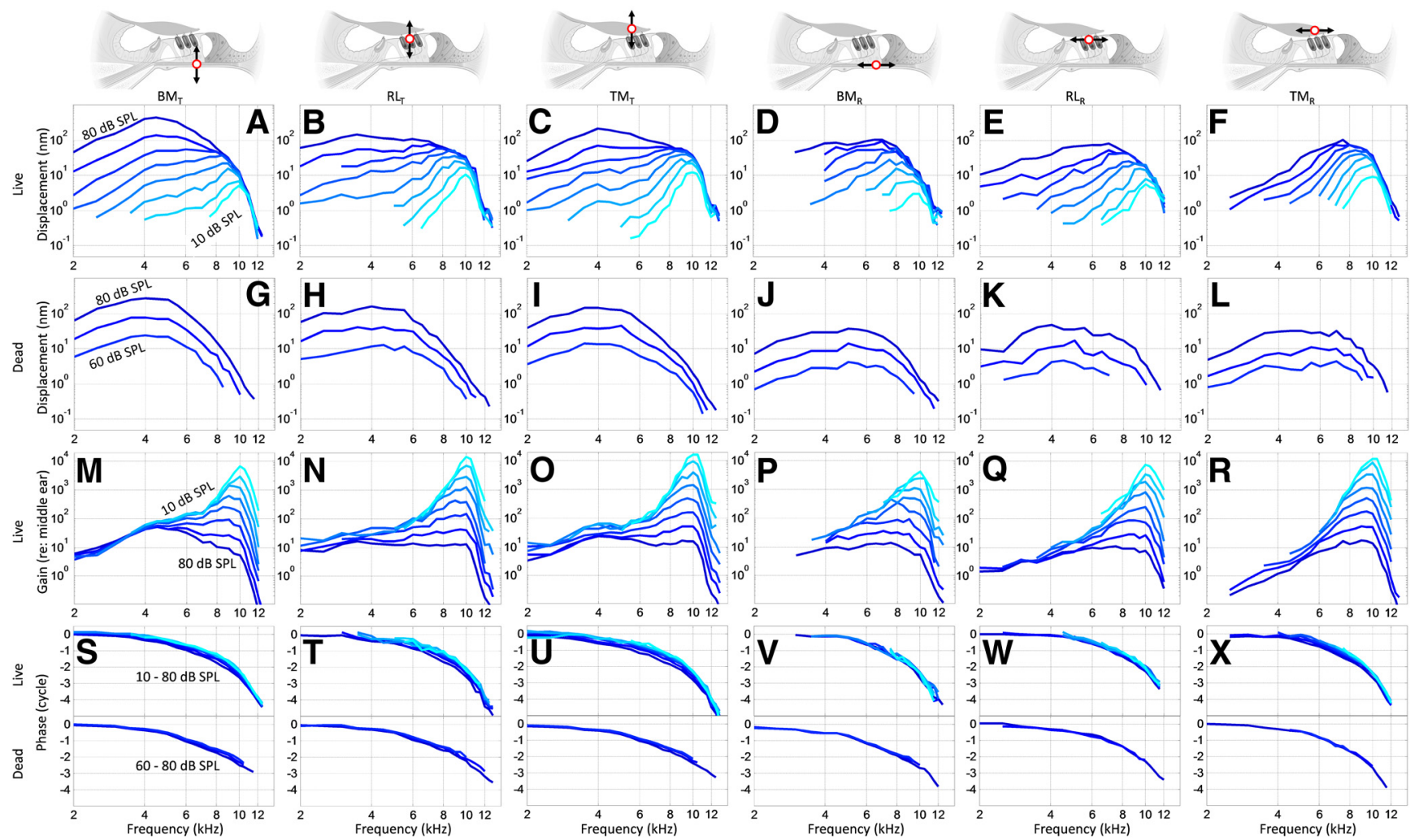

Figure 2. Vibration data for the BM, RL, and TM from a representative (BA/CaJ mouse. Motion in both the transverse (subscript ${ }_{\mathrm{T}}$ ) and radial (subscript ${ }_{\mathrm{R}}$ ) directions are presented. $\boldsymbol{A}-\boldsymbol{F}$, Displacement magnitude in live mice. $\mathbf{G}-\boldsymbol{L}$, Displacement magnitude in dead mice. $\boldsymbol{M}-\boldsymbol{R}$, Gain curves in live mice, calculated by normalizing the displacement magnitude of each structure to the ossicular chain. $\mathbf{S}-\boldsymbol{X}$, Displacement phase in live mice (top curves) and dead mice (bottom curves), normalized to the ossicular chain. The (F in the live mouse was $\sim 10 \mathrm{kHz}$, whereas the frequency of maximal vibration (BF) in the dead mouse was $\sim 5 \mathrm{kHz}$. Thus, there are differences in the frequency response of the cochlear vibrations in the live and dead mouse measured at the same location. This is an equivalent way of demonstrating a shift in the location of the traveling wave peak (i.e., compare the locations of the peaks of the dotted lines in the top and bottom tracings in Fig. 1A).

membrane relative to the optical axis. Thus, if the basilar membrane was flat in the image, the angle was $90^{\circ}$. Vibratory data measured at both angles from the identical position were then plugged into Equation 1 to get the transverse and radial vectors of motion.

Data adjustment and statistical analysis. To average data collected from different mice, vibratory magnitudes and phases were averaged separately, and the mean and SEM for all data points were calculated. Phase unwrapping was performed so that all phases that were averaged together at each frequency were within $\pi$ radians of the mean. For all figures, we did not plot data at those frequency/intensity combinations where the vibratory responses from two or more of the mice included in the average were below the noise floor. Student's paired or nonpaired $t$ tests were used as indicated for comparisons of two groups, and ANOVA testing was used for three or more groups.

Tuning curve sharpness was quantified by calculating the $\mathrm{Q}_{10 \mathrm{~dB}}$. We first identified the frequency of the peak vibratory response at the lowest stimulus intensity used, the CF. The bandwidth $10 \mathrm{~dB}$ below the vibratory magnitude at this frequency was then determined. The $\mathrm{Q}_{10 \mathrm{~dB}}$ is the CF divided by the bandwidth.

Scanning electron microscopy. Inner ears from P35 CBA/CaJ mice were dissected in fixative (2.5\% glutaraldehyde; $4 \%$ formaldehyde; $0.05 \mathrm{~mm}$ HEPES buffer, pH 7.2, $10 \mathrm{~mm} \mathrm{CaCl}_{2}, 5 \mathrm{mM} \mathrm{MgCl}_{2}, 0.9 \% \mathrm{NaCl}$ ). A hole was poked at the apex of the cochlea, and fixative was flushed through the round window. The samples were fixed first for $2 \mathrm{~h}$ at room temperature in this fixative, then in $1 \%$ osmium tetroxide in washing buffer $(0.05 \mathrm{~mm}$ HEPES buffer, $\mathrm{pH} 7.2,10 \mathrm{~mm} \mathrm{CaCl}_{2}, 5 \mathrm{~mm} \mathrm{MgCl}_{2}, 0.9 \% \mathrm{NaCl}$ ) for $1.5 \mathrm{~h}$, and then rinsed extensively in washing buffer. The samples were dissected in the washing buffer to remove the stria vascularis, Reissner's and TMs. The samples were refixed in $1 \%$ osmium tetroxide in washing buffer for $1 \mathrm{~h}$ then rinsed extensively again. Finally, the samples were dehydrated and processed to critical drying point (Autosamdri-815A, Tousimis). The cochleae were mounted on a stud with silver paint and sputter coated with $5 \mathrm{~nm}$ of iridium (EMS150T S; Electron Microscopy Sciences). Samples were imaged at $5 \mathrm{kV}$ with a FEI Magellan $400 \mathrm{XHR}$ Field Emission Scanning Electron at the Stanford Nano Shared Facilities. The length of the tallest row of OHC stereocilia in the apical turn, approximately a half-turn down from the helicotrema (where we made the vibratory measurements), was estimated using the scale bars of the original scanning electron microscopy pictures.

\section{Results}

We studied anesthetized P28-P40 CBA/CaJ mice in vivo. We used VOCTV to measure sound-induced vibrations within the cochlea noninvasively, approximately a half-turn down from the apex (Lee et al., 2015). Because OHC stereocilia are deflected by the radial shear between the RL and the TM, whereas the transverse motion of the BM is the most commonly published measurement of cochlear mechanics, we focused our analyses on these three measurements. To provide a convenient nomenclature, we labeled the vectors of motion by placing a subscript after the structure being measured. Examples include the $\mathrm{BM}_{\mathrm{T}}$, the radial motion of the RL $\left(R L_{R}\right)$, and the radial motion of the TM $\left(T M_{R}\right)$.

Data from one representative mouse are presented as an example (Fig. 2). However, to assess for differences quantitatively, we averaged responses measured from a cohort of six CBA/CaJ mice both living and dead (Fig. 3). One of the mice moved slightly during the euthanasia process and thus only five of the mice were averaged in the dead condition. The transverse and radial motion of all three structures (BM, RL, and TM) were calculated. The CF was defined as the frequency of maximal vibratory amplitude of transverse $\mathrm{BM}$ in a live mouse at the lowest stimulus intensity tested, which was $10 \mathrm{~dB}$ SPL. Because the CF at the recording 


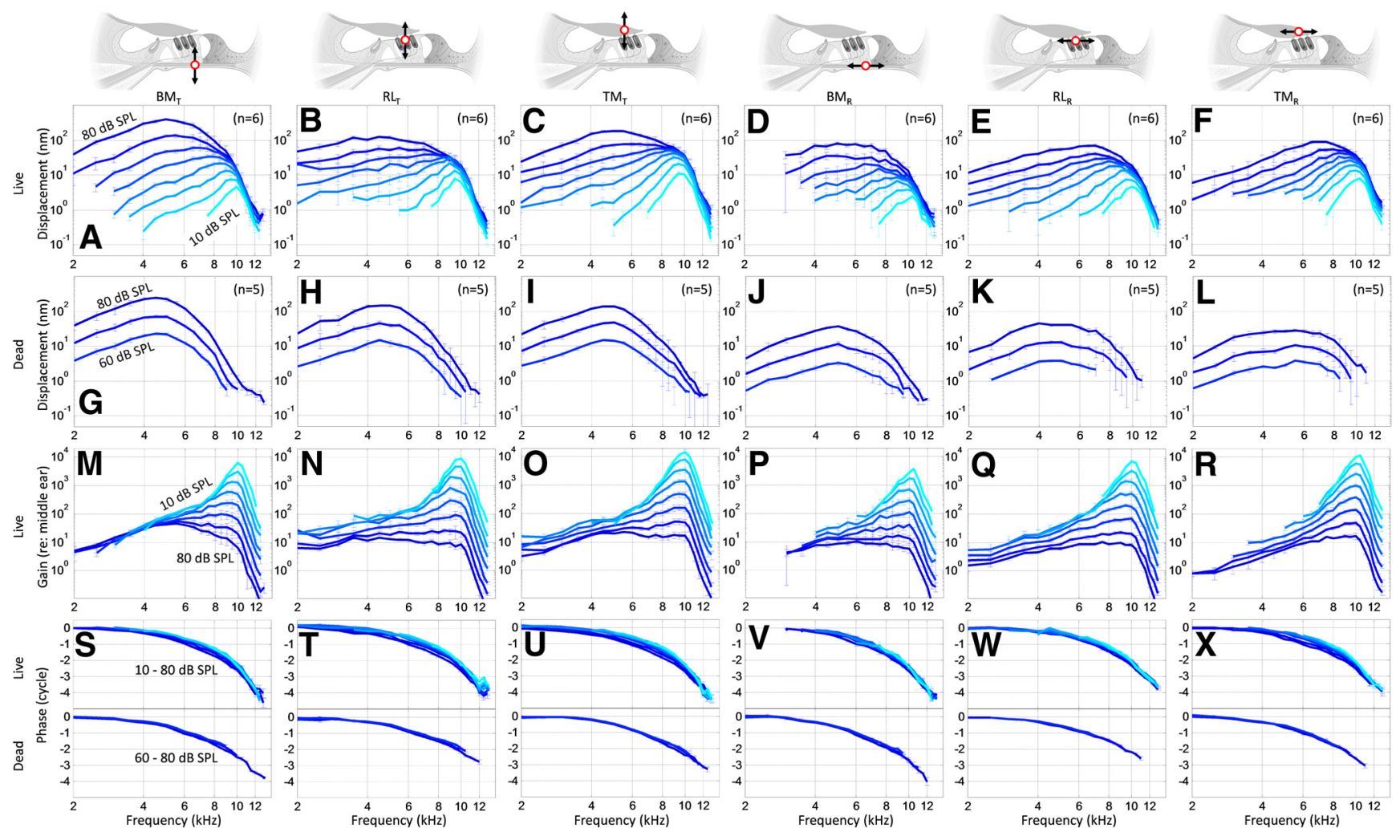

Figure 3. Average vibration data for the BM, RL, and TM from 5 or 6 CBA/CaJ mice. Motion in both the transverse (subscript $\mathrm{T}_{\mathrm{T}}$ ) and radial (subscript $\mathrm{R}_{\mathrm{R}}$ ) directions are presented. $\boldsymbol{A}-\boldsymbol{F}$, Displacement magnitude in live mice. $\mathbf{G}-\mathbf{L}$, Displacement magnitude in dead mice. $\boldsymbol{M}-\boldsymbol{R}$, Gain curves in live mice, calculated by normalizing the displacement magnitude of each structure to the ossicular chain. $S-\boldsymbol{X}$, Displacement phase in live mice (top curves) and dead mice (bottom curves). Error bars indicate SEM.

locations varied slightly between mice, we frequency-shifted the data by up to $\pm 0.5 \mathrm{kHz}$ so that the CF for all mice became $10 \mathrm{kHz}$. This facilitated averaging of the responses.

\section{$\mathrm{BM}_{\mathrm{T}}, \mathrm{RL}_{\mathrm{T}}$, and $\mathrm{TM}_{\mathrm{T}}$}

In live mice, the $\mathrm{BM}_{\mathrm{T}}$ demonstrated the classic findings of cochlear amplification (Figs. 2A, 3A) (Robles and Ruggero, 2001). First, there was compression of the vibratory responses, consistent with a nonlinear active process that provides more gain for low-intensity than for high-intensity stimuli. This was particularly obvious near the CF $(10 \mathrm{kHz})$. Second, the frequency of maximal vibration (termed the best frequency $[\mathrm{BF}]$ ) increased as the stimulus intensity decreased so that it was $5 \mathrm{kHz}$ at $80 \mathrm{~dB}$ sound pressure level (SPL) compared with $10 \mathrm{kHz}$ at $10 \mathrm{~dB}$ SPL. Last, the frequency response of the vibration became more sharply tuned as the stimulus intensity was decreased. In contrast, dead mice had purely passive responses, which were tuned broadly at $5 \mathrm{kHz}$ and varied linearly with stimulus intensity (i.e., there was no compression) (Figs. 2G, 3G).

The transverse motion of the $\mathrm{RL}\left(\mathrm{RL}_{\mathrm{T}}\right)$ and $\mathrm{TM}\left(\mathrm{TM}_{\mathrm{T}}\right)$ were then compared with the $\mathrm{BM}_{\mathrm{T}}$. At the lowest stimulus intensity tested, 10 $\mathrm{dB}$ SPL, the $\mathrm{RL}_{\mathrm{T}}$ and $\mathrm{TM}_{\mathrm{T}}$ had larger vibratory magnitudes than the $\mathrm{BM}_{\mathrm{T}}$ at the CF (Fig. $3 A-C ; 10 \mathrm{kHz} ; \mathrm{BM}_{\mathrm{T}}: 4.90 \pm 0.71 \mathrm{~nm} ; \mathrm{RL}_{\mathrm{T}}$ : $8.07 \pm 1.89 \mathrm{~nm} ; \mathrm{TM}_{\mathrm{T}}: 12.18 \pm 2.37 \mathrm{~nm} ; p=0.07$ and $p=0.02$ respectively, paired $t$ test). However, the phase responses of the $\mathrm{BM}_{\mathrm{T}}$, $\mathrm{RL}_{\mathrm{T}}$, and $\mathrm{TM}_{\mathrm{T}}$ at CF were similar (Fig. $3 S-U ; \mathrm{BM}_{\mathrm{T}}:-2.33 \pm 0.06$ cycle; $\mathrm{RL}_{\mathrm{T}}:-2.25 \pm 0.04$ cycle; $\mathrm{TM}_{\mathrm{T}}:-2.28 \pm 0.07$ cycle; $p=0.645$, ANOVA). These findings are consistent with recent published reports (Lee et al., 2015; Ren et al., 2016).

Interestingly, however, we found that the frequency responses of the $\mathrm{RL}_{\mathrm{T}}$ and $\mathrm{TM}_{\mathrm{T}}$ were flatter than that of the $\mathrm{BM}_{\mathrm{T}}$, particularly at low frequencies. This was most obvious after normalizing the vibratory responses to that of the middle ear to show the cochlear gains (Fig. 3M-O). We calculated the stimulus level dependence of the gain at CF by dividing the gain at $10 \mathrm{~dB}$ SPL by that at $80 \mathrm{~dB}$ SPL. At CF, there was no difference between the three calculations $\left(10 \mathrm{kHz} ; \mathrm{BM}_{\mathrm{T}}: 59.6 \pm 2.4 \mathrm{~dB} ; \mathrm{RL}_{\mathrm{T}}: 60.4 \pm 1.3 \mathrm{~dB} ; \mathrm{TM}_{\mathrm{T}}\right.$ : $58.8 \pm 1.7 \mathrm{~dB} ; p=0.820$, ANOVA). We repeated this calculation below $\mathrm{CF}$, although we had to use the gain at $30 \mathrm{~dB}$ SPL rather than $10 \mathrm{~dB}$ SPL because of the lower vibratory magnitudes at this frequency. This demonstrated that, below the CF, the $\mathrm{RL}_{\mathrm{T}}$ and the $\mathrm{TM}_{\mathrm{T}}$ clearly had larger level dependences to their gain $(5 \mathrm{kHz}$; $\mathrm{BM}_{\mathrm{T}}: 5.3 \pm 0.7 \mathrm{~dB} ; \mathrm{RL}_{\mathrm{T}}: 16.5 \pm 2.2 \mathrm{~dB} ; \mathrm{TM}_{\mathrm{T}}: 12.8 \pm 1.3 \mathrm{~dB} ; p=$ 0.020 and $p=0.049$ respectively, paired $t$ test). This argues that $\mathrm{OHCs}$ are activated below $\mathrm{CF}$ and produce force to displace the $\mathrm{RL}$ and TM, even though this is not as strongly represented in the $\mathrm{BM}_{\mathrm{T}}$ response, suggesting that the impedances of the RL and TM are different from that of the BM.

Regardless of the low-level amplification found at low frequencies, these data demonstrate that, at the tonotopic location of the cochlea we studied, the passive mechanics of the basilar membrane were broadly tuned at $\sim 5 \mathrm{kHz}$, whereas the active mechanics associated with cochlear amplification were sharply tuned at $\sim 10 \mathrm{kHz}$. Therefore, the rest of our analyses focused on comparing the $\mathrm{RL}_{\mathrm{R}}$ and $\mathrm{TM}$ to the $\mathrm{BM}_{\mathrm{T}}$ at or near these two frequencies.

\section{$\mathrm{RL}_{\mathrm{R}}$ and $\mathrm{TM} \mathrm{R}_{\mathrm{R}}$}

The radial motion of the $\mathrm{RL}\left(\mathrm{RL}_{\mathrm{R}}\right)$ and $\mathrm{TM}\left(\mathrm{TM}_{\mathrm{R}}\right)$ demonstrated features similar to, but not exactly like their transverse motion. Thus, there were compressive nonlinearities in living mice that disappeared after death (Fig. $3 E, F$ ), and the phase responses 

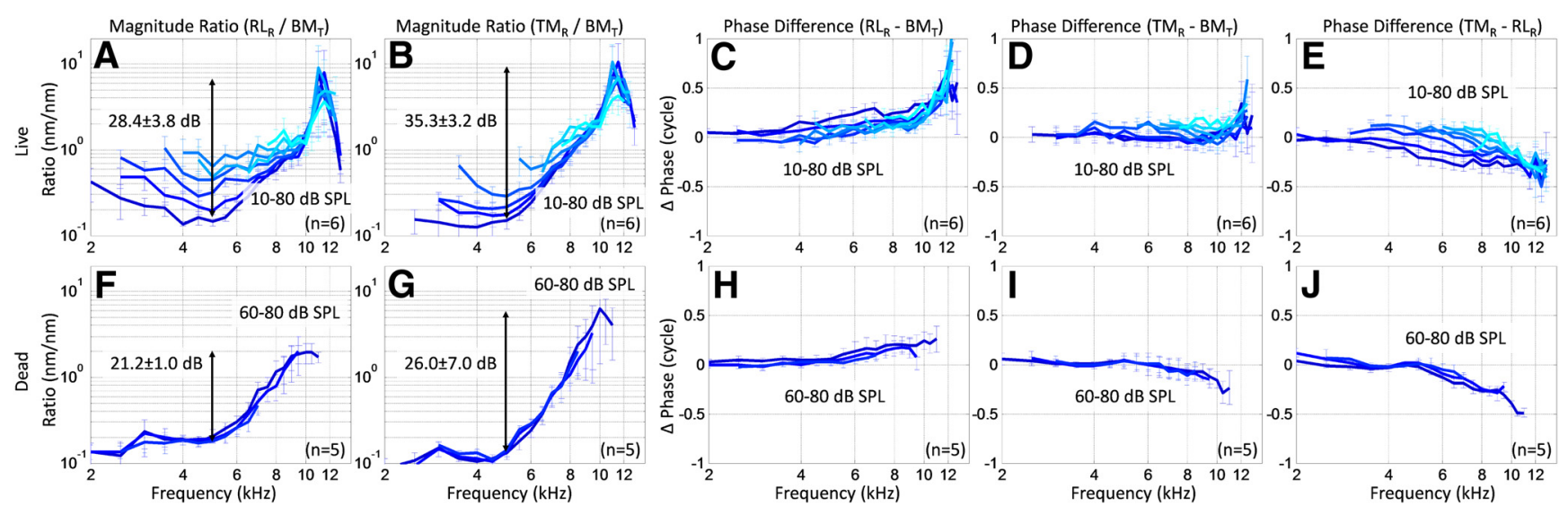

Figure 4. Radial tuning in 6 living (top row) and dead (bottom row) $C B A / C$ aJ mice. $A, B, F, G$, The magnitudes of the $R L_{R}$ and $T M_{R}$ were normalized to the $B M_{T}$. The differences in the response amplitudes at 5 and $10 \mathrm{kHz}$ to $80 \mathrm{~dB}$ SPL stimuli are highlighted (arrows, mean \pm SEM). These data show that $R L_{R}$ and $T_{R}$ are tuned to be maximal near the characteristic frequency of $\sim 10 \mathrm{kHz}$, in both live and dead mice. $\boldsymbol{C}, \boldsymbol{D}, \boldsymbol{H}, \boldsymbol{I}$, The phase of $R L_{R}$ and $T M_{R}$ normalized to the phase of $B M_{T} . \boldsymbol{E}$, J, The phase difference between $T M_{R}$ and $R L_{R}$. Error bars indicate $S E M$.

demonstrated a progressive lag as the frequency was increased (Fig. $3 W, X$ ). However, the shapes of the curves were not identical. In live mice (Fig. $3 A, E, F$ ), the $C F$ was similar among the three measurements $\left(\mathrm{BM}_{\mathrm{T}}: 10.0 \pm 0 \mathrm{kHz} ; \mathrm{RL}_{\mathrm{R}}: 10.25 \pm 0.17 \mathrm{kHz} ; \mathrm{TM}_{\mathrm{R}}\right.$ : $10.37 \pm 0.12 \mathrm{kHz} ; p=0.123$, ANOVA). However, the BF at $80 \mathrm{~dB}$ SPL was higher for the $R L_{R}$ and $T_{R}$ measurements $\left(B M_{T}\right.$ : $5.25 \pm 0.25 \mathrm{kHz} ; \mathrm{RL}_{\mathrm{R}}: 6.58 \pm 0.24 \mathrm{kHz} ; \mathrm{TM}_{\mathrm{R}}: 7.00 \pm 0.29 \mathrm{kHz}$; $p=0.005$ and $p=0.002$ respectively, paired $t$ test). The tuning curve sharpness at $10 \mathrm{~dB}$ SPL, defined by the $\mathrm{Q}_{10 \mathrm{~dB}}$, was similar for the three measurements $\left(\mathrm{BM}_{\mathrm{T}}: 3.47 \pm 0.14 ; \mathrm{RL}_{\mathrm{R}}: 3.52 \pm 0.17\right.$; $\mathrm{TM}_{\mathrm{R}}: 3.71 \pm 0.28 ; p=0.692$, ANOVA). The level dependence of the gain was similar between the $\mathrm{BM}_{T}, \mathrm{RL}_{\mathrm{R}}$, and $\mathrm{TM}_{\mathrm{R}}$ at $\mathrm{CF}$ (10 kHz, $10-80$ dB SPL comparison; Fig. $3 M, Q, R ; \mathrm{BM}_{\mathrm{T}}: 59.6 \pm 2.4$ $\mathrm{dB} ; \mathrm{RL}_{\mathrm{R}}: 58.9 \pm 1.2 \mathrm{~dB} ; \mathrm{TM}_{\mathrm{R}}: 55.6 \pm 3.1 \mathrm{~dB} ; p=0.475$, ANOVA). However, the differences in the level dependence of the gain were prominent below $\mathrm{CF}\left(5 \mathrm{kHz} ; \mathrm{BM}_{\mathrm{T}}: 4.1 \pm 0.5 \mathrm{~dB} ; \mathrm{RL}_{\mathrm{R}}: 16.2 \pm 2.5\right.$ $\mathrm{dB} ; \mathrm{TM}_{\mathrm{R}}: 11.2 \pm 1.0 ; p=0.02$ and $p=0.05$ respectively, paired $t$ test). Together with the previously presented data on transverse vibrations, these data indicate that, below $\mathrm{CF}$, the transverse and radial movements of both the RL and TM are more sensitive measures of amplification than the transverse movement of the BM.

In dead mice (Fig. $3 G, K, L$ ), the radial motion of the RL and $\mathrm{TM}$ and the transverse motion of the BM all demonstrated linear, passive responses. However, visual inspection of shapes of the tuning curves suggested differences in tuning. We therefore compared the $Q_{10} \mathrm{~dB}$ values of these three structures $\left(\mathrm{BM}_{\mathrm{T}}: 1.23 \pm 0.11 ; \mathrm{RL}_{\mathrm{R}}: 1.06 \pm 0.06 ; \mathrm{TM}_{\mathrm{R}}: 0.86 \pm 0.04\right)$ and found that the $\mathrm{Q}_{10 \mathrm{~dB}}$ of the $\mathrm{BM}_{\mathrm{T}}$ was not statistically different from that of the $\mathrm{RL}_{R}$, but the $\mathrm{Q}_{10 \mathrm{~dB}}$ of the $\mathrm{BM}_{\mathrm{T}}$ was more sharply tuned than that of the $\operatorname{TM}_{\mathrm{R}}(p=0.295$ and $p=0.035$, respectively). These differences in tuning primarily appeared to extend the high-frequency response of the $\mathrm{TM}_{\mathrm{R}}$ (and to a lesser extent, the high-frequency response of the $R L_{R}$ ) compared with the $\mathrm{BM}_{\mathrm{T}}$. In contrast, the low-frequency responses were similar between the three measurements.

\section{Normalized $R_{R}$ and $T M_{R}$}

To better quantify their frequency responses, we normalized the radial motion of the RL and TM to the transverse motion of the BM (Fig. 4A, $B, F, G$ ). In live mice, these analyses revealed sharply tuned responses centered at $11 \mathrm{kHz}$. In dead mice, a similar pattern was found. However, because the raw magnitudes of all vi- brometry measurements diminished $>11 \mathrm{kHz}$, we could not assess whether or not the normalized response dropped off above this frequency.

In live mice, there was evidence for gain that was intensitydependent at $5 \mathrm{kHz}$, consistent with the low level of cochlear gain we identified in the RL and TM vibratory measurements below CF. However, there was no intensity dependence to the response at $11 \mathrm{kHz}$. Dead mice had no intensity dependence to these normalized responses at any frequency.

The increases in the relative radial motions of the RL and TM when comparing the responses to 11 and $5 \mathrm{kHz}$ stimuli were substantial. In some cases, this difference reached nearly $40 \mathrm{~dB}$ (i.e., $100 \times$ greater; Fig. $4 A, B, F, G$, arrows). Importantly, however, these differences in the frequency responses were largest when cochlear amplification was least relevant (i.e., live mice at an $80 \mathrm{~dB}$ SPL stimuli or dead mice at any stimulus intensity). Therefore, it appears that, because of passive filtering unrelated to $B M$ mechanics, the $R_{R}$ and $T M_{R}$ are reduced compared with the $\mathrm{BM}_{\mathrm{T}}$ below at frequencies considerably below the CF but are increased compared with the $\mathrm{BM}_{\mathrm{T}}$ near and at the $\mathrm{CF}$.

The relative phase also changed as a function of frequency and intensity (Fig. $4 C, D, H, I$ ). In both live and dead mice, the $\mathrm{RL}_{\mathrm{R}}$ phase led the $\mathrm{BM}_{\mathrm{T}}$ phase as the stimulus frequency was increased. In live mice, the $\mathrm{TM}_{R}$ phase demonstrated a similar response, whereas in dead mice the $\mathrm{TM}_{R}$ phase lagged the $\mathrm{BM}_{T}$ phase. The phase of the radial motion of the TM demonstrated a frequencydependent lag relative to the RL, which extended to lower frequencies as the stimulus intensity was increased (Fig. $4 E, J$ ).

These findings indicate that the radial motion of the hair cell epithelium is tuned differently than the BM upon which it sits. If tuning were identical, the normalized responses would show no frequency dependence. Instead, radial motion is enhanced near $\mathrm{CF}$. Because this phenomenon is found in dead mice, OHC force production is not necessary to provide this tuning. Thus, we demonstrate a passive, frequency-dependent contribution to cochlear filtering that is distinct from BM filtering. This is the key finding of this report.

\section{Estimation of stereociliary deflection}

We then sought to predict the effect that radial tuning of the TM and RL would have on OHC stimulation. OHC stereocilia are rooted in the cuticular plates at the apical end of the hair cell, which form the RL. The tips of the tallest row of stereocilia are 

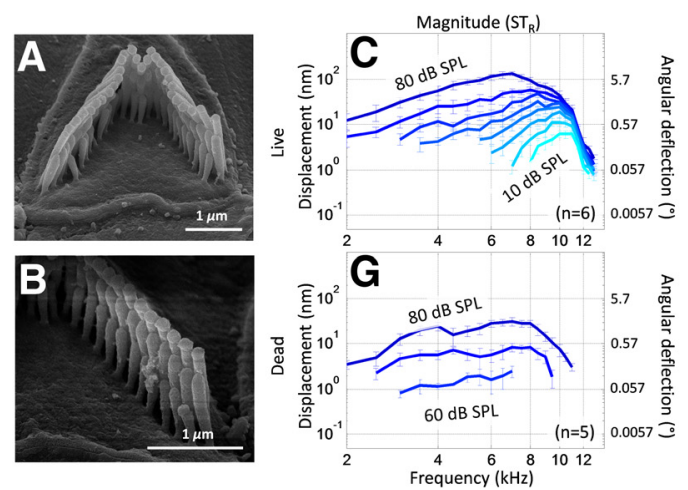
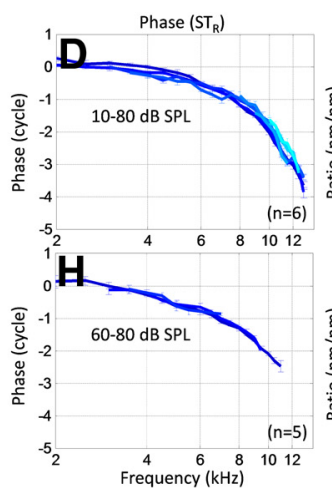
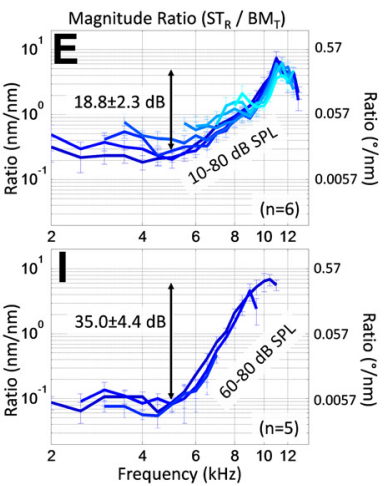

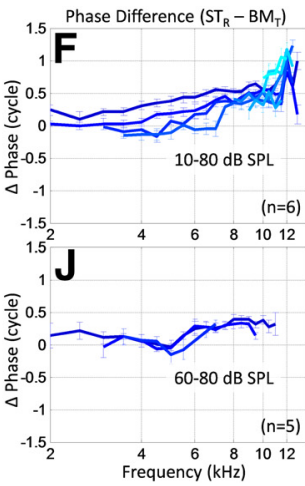

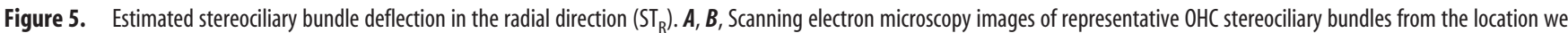
measured vibratory responses. We estimated the length of the tallest row of stereocilia to be $1 \mu \mathrm{m}$ and used this to estimate angular deflection of the bundle from the displacement data. $C-J$, Data from 6 live (top row) and 5 dead (bottom row) mice are shown, including estimates of the raw magnitude $(\boldsymbol{C}, \boldsymbol{G})$ and phase $(\boldsymbol{D}, \boldsymbol{H})$ estimates and the responses normalized to the $B M_{T}(\boldsymbol{E}, \boldsymbol{F}, \boldsymbol{I}, \boldsymbol{J})$. Error bars indicate SEM. The differences in the normalized magnitude responses at 5 and $10 \mathrm{kHz}$ to $80 \mathrm{~dB}$ SPL stimuli are highlighted (arrows, mean \pm SEM) and demonstrate tuning at the characteristic frequency in both live and dead mice.

attached to the undersurface of the TM. Thus, performing a vector subtraction of the $\mathrm{TM}_{\mathrm{R}}$ and RL provides an estimate of stereociliary displacement $\left(\mathrm{ST}_{\mathrm{R}}\right)$ as follows:

$$
\overline{\mathrm{ST}_{\mathrm{R}}}=\overline{\mathrm{TM}_{\mathrm{R}}}-\overline{\mathrm{RL}_{\mathrm{R}}}
$$

This calculation takes into account the vibratory magnitude and phase of each structure.

It is important to recognize that this calculation should only be considered an estimate because we cannot visualize OHC stereocilia with our VOCTV system. We must therefore assume that the vibration data at the points we measured in the TM and RL accurately represent what is actually happening at the tips and base of the stereocilia, respectively. These are reasonable assumptions because previous data have demonstrated that the RL is rigid and vibrates as a stiff element (Tilney et al., 1980; Drenckhahn et al., 1982; Furness et al., 2008; Nowotny and Gummer, 2011). Similarly, ex vivo data argue that stereociliary bundles should drive the TM to vibrate as a single bulk at one cochlear location, essentially acting like a series of coupled rigid bodies (Ghaffari et al., 2007; Gu et al., 2008). The limited in vivo data available also support this notion that the vibration in the body of the $\mathrm{TM}$ is the same as that along the bottom edge, where the $\mathrm{OHC}$ stereociliary bundles attach (Lee et al., 2015). However, the stereocilia may undergo dynamic length changes, causing the tip to indent the TM and move more than predicted (Hakizimana et al., 2012). Furthermore, the deflection of the stereocilia may not be precisely at the $90^{\circ}$ radial angle, and so the absolute values we measure may be off by the cosine of the actual angle.

To estimate the angular deflection of the stereociliary bundle, we measured the length of the OHC stereocilia in our mouse model. Scanning electron microscopy was performed in the $\mathrm{CBA} / \mathrm{CaJ}$ mouse cochlea at the location where we made the vibratory measurements, a half-turn down from the apex. From the images, the length of the tallest row of OHC stereocilia in the location where we made the vibratory measurements was $\sim 1 \mu \mathrm{m}$ (Fig. 5A,B). This measurement is consistent with previously published data. For example, while our measurement is shorter than published measurements of $\mathrm{OHC}$ stereocilia from the apical end of P6-P7 Swiss Webster, CD-1, or C57BL/6 mice, which range from $\sim 2$ to $3.7 \mu \mathrm{m}$ (Stauffer and Holt, 2007; Lelli et al., 2009), it is larger than measurements made from adult C57BL/6 mice, which were $\sim 0.6 \mu \mathrm{m}$ (Narayanan et al., 2015). Thus, we estimated the angular deflection of the stereociliary bundle $(\Theta)$ using the length of the tallest row of OHC stereocilia $(\ell=1 \mu \mathrm{m})$ with the following formula:

$$
\Theta=\arctan \left(\mathrm{ST}_{\mathrm{R}} / \ell\right)
$$

Stereociliary deflection estimates demonstrated features of cochlear amplification in live mice, including compression and intensity-dependent shifts in the BF and tuning curve sharpness (Fig. 5C, D, G,H). For example, at $10 \mathrm{~dB}$ SPL, the peak magnitude of stereociliary displacement was $8.3 \pm 0.7 \mathrm{~nm}\left(0.49 \pm 0.04^{\circ}\right)$ at the CF of $10.2 \pm 0.3 \mathrm{kHz}$. At $80 \mathrm{~dB}$ SPL, the peak magnitude of stereociliary displacement was $151.2 \pm 9.6 \mathrm{~nm}\left(8.60 \pm 0.55^{\circ}\right)$ at the $\mathrm{BF}$ of $6.5 \pm 0.4 \mathrm{kHz}$. In contrast, dead mice demonstrated linear responses and reduced stereociliary deflection. At $80 \mathrm{~dB}$ SPL in live mice, the BF of stereociliary deflection was higher than the $\mathrm{BF}$ of the transverse motion of the $\mathrm{BM}$ (compare Fig. $5 C$ vs Fig. $3 A ; 7.1 \pm 0.4 \mathrm{kHz}$ vs $5.2 \pm 0.3 \mathrm{kHz}$ for live mice, $p=0.011$, paired $t$ test) and was similar in dead mice. Finally, the phase of stereociliary deflection was similar in live and dead mice.

We normalized the estimated deflection of the stereocilia to the $\mathrm{BM}_{\mathrm{T}}$ (Fig. $5 E, F, I, J$ ). In both live and dead mice, the relative deflection of the stereocilia was greatest at $\sim 10-11 \mathrm{kHz}$. Compared with the relative stereociliary deflection at $5 \mathrm{kHz}$, this increased response ranged from $18.8 \pm 2.3$ to $35.0 \pm 4.4 \mathrm{~dB}$ (i.e., $8-56 \times$ greater). In both live and dead mice, the phase of stereociliary deflection led the phase of the basilar membrane at higher frequencies.

Thus, these estimates indicate that, although OHCs are stimulated over a broad frequency range, the feedback loop associated with the forces they produce is sharply tuned relative to BM motion. Our data suggest that feedback associated with the amplification process is reduced at frequencies far below the CF, whereas feedback is enhanced near the CF.

\section{Tonotopic distribution of stereociliary tuning}

To verify that the frequency dependence of our estimates of $\mathrm{OHC}$ stereociliary deflection reflected the tonotopic map of the cochlea, we measured the $\mathrm{TM}_{\mathrm{R}}$ and RL at three different longitudinal locations from three different mice (Fig. 6). The CFs of these locations were $10,11.5$, and $12.5 \mathrm{kHz}$. All of the estimates of $\mathrm{OHC}$ stereociliary deflection magnitude and phase had similar patterns that were simply shifted in frequency. After death, stereociliary deflection was reduced and became linear; however, the phase was unaffected. In two of the mice, we were also able to record the 


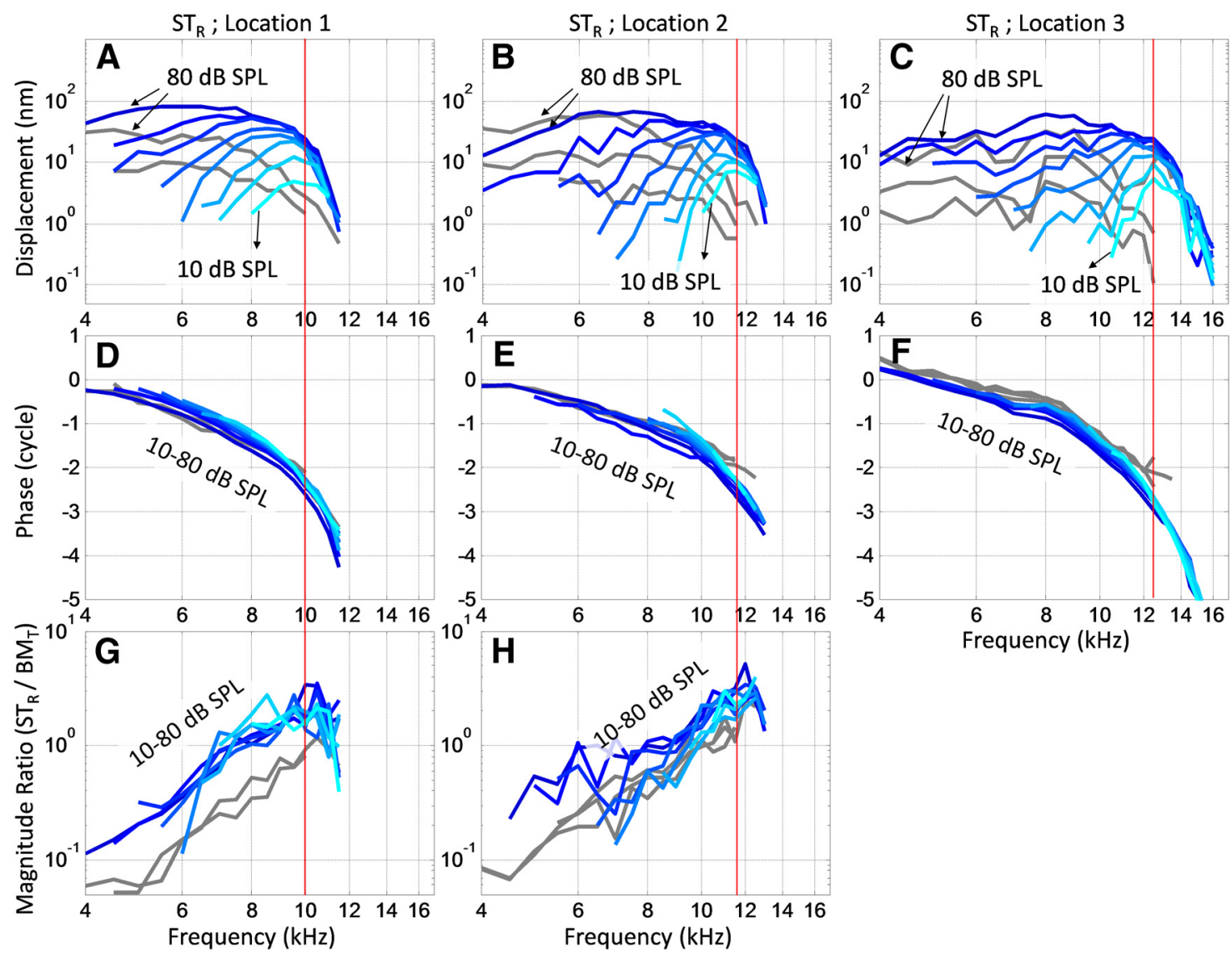

Figure 6. Representative stereociliary displacement estimates in the radial direction $\left(\mathrm{ST}_{\mathrm{R}}\right)$ at three different longitudinal locations (Locations 1-3) in $(B A / C a J$ mice when live (blue) or postmortem (gray). Each measurement point was shifted by $\sim 200 \mu \mathrm{m}$ from each other, and the (Fs were 10, 11.5, and $12.5 \mathrm{kHz}$ (red lines). A-C, Displacement magnitude of ST $\mathrm{R}_{\mathrm{R}}$. D-F, Displacement phase of $S T_{R}, G, H$, Displacement magnitude of $S T_{R}$ normalized to that of $\mathrm{BM}_{\mathrm{T}}$. A ratio could not be calculated for location 3 because movement was measured from only one image that was collected at a purely radial angle $\left(\theta=90^{\circ}\right)$, due to anatomic limitations.

$\mathrm{BM}_{\mathrm{T}}$. Normalizing the stereociliary deflection to basilar membrane transverse motion revealed a frequency shift in the maximal point of the magnitude ratio, consistent with a shift in the tonotopic map. In the third mouse, we could not make this comparison to the basilar membrane transverse motion because the angle was limited surgically to only permit a purely radial measurement. Together, these findings confirm that $\mathrm{OHC}$ stereociliary bundles are stimulated relatively more at frequencies above the $\mathrm{BF}$ of the basilar membrane, and that this occurs in dead mice, where OHCs do not produce force. This suggests that the stereociliary bundles of OHCs are tuned by passive mechanical properties so that they are stimulated with the proper frequency response for their tonotopic location along the length of the cochlea.

\section{What is the role of the TM?}

Radial tuning of the TM has been shown in vitro (Ghaffari et al., 2007; Sellon et al., 2015). To test whether the radial tuning we measured in vivo derived from the TM, we studied Tecta ${ }^{\mathrm{Cl} 509 \mathrm{G} / \mathrm{C} 1509 \mathrm{G}}$ mice. In this model, the TM is malformed, is completely elevated off of the epithelium, does not contact stereocilia from any of the three rows of OHCs, and does not stimulate the OHCs (Xia et al., 2007; Liu et al., 2011). Therefore, for the purposes of this experiment, the radial motion of the RL is independent of TM motion, and the presence or absence of radial tuning can be assessed. On the other hand, because the TM will be stimulated by the fluid between it and the underlying hair cell epithelium, its motion will not be independent of RL motion. Furthermore, the TM has altered mechanical properties because of the Tecta mutation, and thus its response is unlikely to reflect that of a normal TM.

The transverse vibratory response of the basilar membrane was passive and, like dead $\mathrm{CBA} / \mathrm{CaJ}$ mice, peaked at $4-5 \mathrm{kHz}$ (Fig. $7 A, F)$. The $\mathrm{RL}_{\mathrm{R}}$, although passive like the $\mathrm{BM}_{\mathrm{T}}$, had an enhanced response at higher frequencies somewhat like that found in dead CBA/CaJ mice (Fig. $7 B, G$ ). $\mathrm{TM}_{\mathrm{R}}$ was also present, which surprisingly demonstrated a second peak centered at $10 \mathrm{kHz}$ (Fig. $7 C, H)$. Whereas the phase of the $\mathrm{BM}_{\mathrm{T}}$ and $\mathrm{RL}_{\mathrm{R}}$ responses was similar, the $\mathrm{TM}_{\mathrm{R}}$ had less of a frequency-dependent phase lag. When normalized to the $\mathrm{BM}_{\mathrm{T}}$, both the RL and TM demonstrated enhanced vibration magnitude at $10 \mathrm{kHz}$ compared with $5 \mathrm{kHz}$ like in dead CBA/CaJ mice (Fig. $7 D, E$ ). This enhancement was larger for the TM compared with the $\mathrm{RL}\left(\mathrm{RL}_{\mathrm{R}}: 13.1 \pm 3.0 \mathrm{~dB}\right.$, $\mathrm{TM}_{\mathrm{R}} 32.1 \pm 5.6 \mathrm{~dB}, p=0.017$, paired $t$ test).

The phase difference between the $\mathrm{RL}_{\mathrm{R}}$ and the $\mathrm{BM}_{\mathrm{T}}$ was similar to that of dead CBA/CaJ mice (Fig. 7I). However, the phase difference between the $\mathrm{TM}_{\mathrm{R}}$ and the $\mathrm{BM}_{\mathrm{T}}$ led that of dead CBA/CaJ mice near the $\mathrm{CF}$ (Fig. $7 J$ ). For example, at $10 \mathrm{kHz}$ the $\mathrm{TM}_{\mathrm{R}}$ phase led the $\mathrm{BM}_{\mathrm{T}}$ phase by $0.74 \pm 0.15$ cycles in Tecta ${ }^{\mathrm{C} 1509 \mathrm{G} / \mathrm{C} 1509 \mathrm{G}}$ mice but lagged by $0.21 \pm 0.08$ cycles in dead CBA/CaJ mice, a phase shift of nearly one cycle ( $p=0.013$, paired $t$ test). These findings were paralleled in the transverse motion of the RL and TM. Consistent with a lack of tethering between the TM and the RL, the phase of the transverse motion of the transverse motion of the TM and basilar membrane differed 

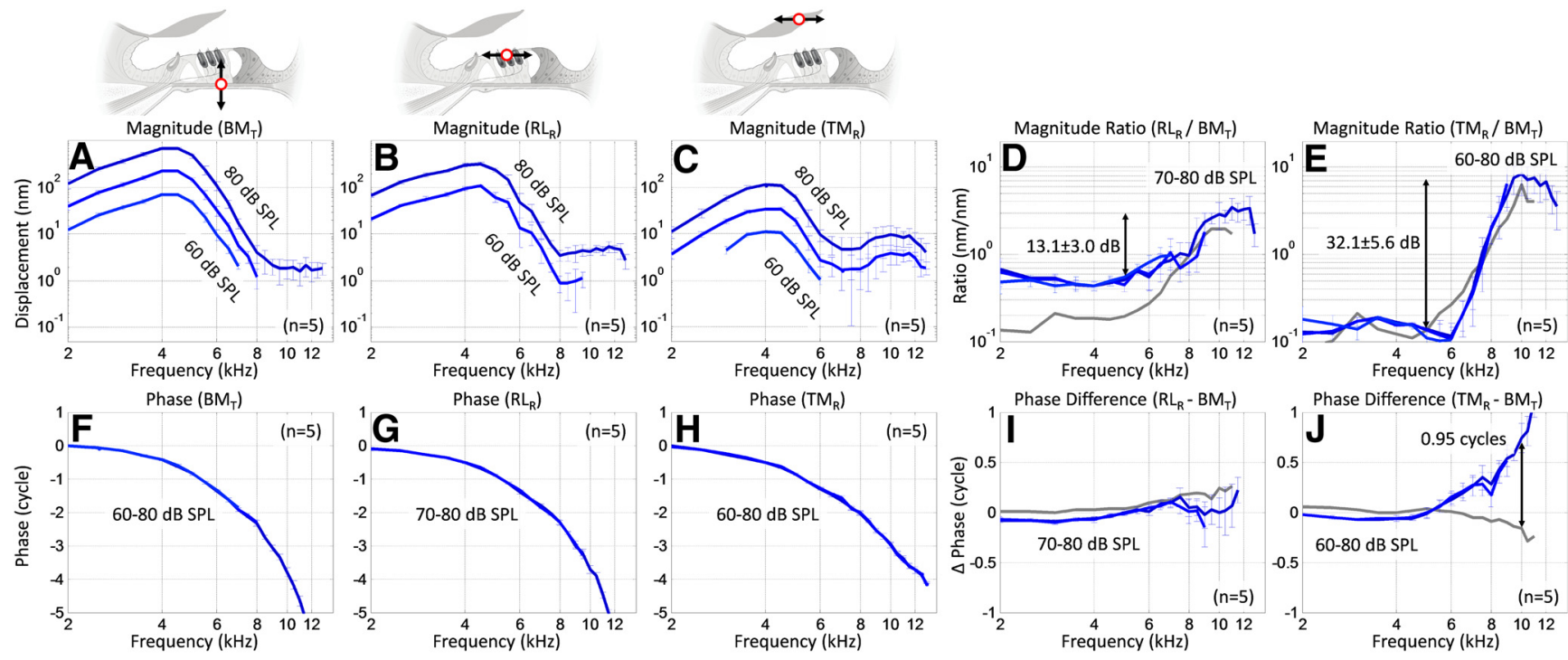

Figure 7. $B M_{T}, R L_{R}$, and $T M_{R}$ motion in 5 Tecta ${ }^{15096 / C 1509 G}$ mice. $\boldsymbol{A}-\boldsymbol{C}$, Displacement magnitudes of $B M_{T}, R L_{R}$, and $T M_{R}$. F- $\boldsymbol{H}$, Displacement phase of $B M_{T}, R L_{R}$, and $T M_{R}$. D, E, The magnitude of $\mathrm{RL}_{\mathrm{R}}$ and $\mathrm{TM}_{\mathrm{R}}$ normalized to the magnitude of $\mathrm{BM}_{\mathrm{T}}$. The differences in the responses at 5 and $10 \mathrm{kHz}$ to $80 \mathrm{~dB} \mathrm{SPL} \mathrm{stimuli} \mathrm{are} \mathrm{highlighted} \mathrm{(arrows,} \mathrm{mean} \pm \mathrm{SEM}$ ). As in (BA/CaJ mice, the radial motion of both structures was tuned to the characteristic frequency in both live and dead mice. The normalized responses of dead CBA/CaJ mice to $80 \mathrm{~dB} \mathrm{SPL} \mathrm{stimuli} \mathrm{taken} \mathrm{from} \mathrm{Figure} 4 F$, $G$ are shown for reference (gray). $I, J$, The phase of $R L_{R}$ and $T M_{R}$ minus the phase of $B M_{T}$. The normalized responses of dead CBA/CaJ mice to $80 \mathrm{~dB} \mathrm{SPL} \mathrm{stimuli} \mathrm{taken} \mathrm{from} \mathrm{Figure} 4 H$, I are shown for reference (gray). There was a large phase difference in the TM phase between CBA/CaJ and Tecta ${ }^{\mathrm{C} 15096 / \mathrm{C15096}}$ mice, which was quantified at $10 \mathrm{kHz}$ (arrow).
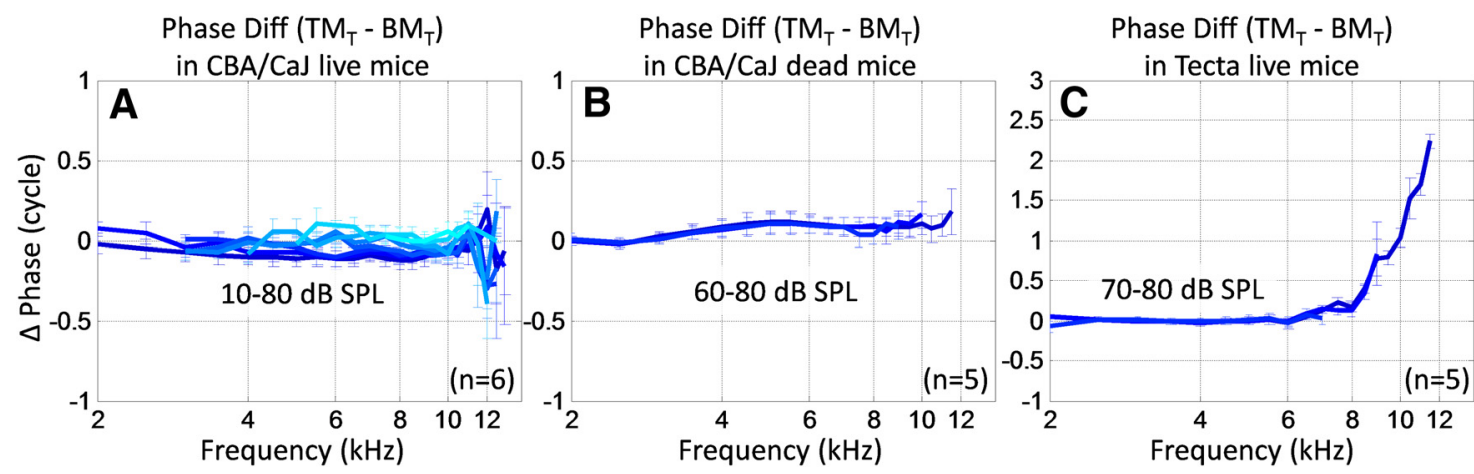

Figure 8. Phase difference between the transverse vibration of the TM and the BM: $(\boldsymbol{A})$ in 6 live CBA/CaJ mice; $(\boldsymbol{B})$ in 5 dead CBA/CaJ mice; and $(\boldsymbol{C})$ in 5 live Tecta ${ }^{{ }^{115096 / C 1509 G}}$ mice. The TM in Tecta ${ }^{15096 /(1509 G}$ mice has a phase difference from the BM near $C F$, whereas there is no phase difference in wild-type mice.

near the $\mathrm{CF}$ in Tecta ${ }^{\mathrm{C} 1509 \mathrm{G} / \mathrm{C} 1509 \mathrm{G}}$ mice but not in CBA/CaJ mice (Fig. 8).

The frequency-dependent phase differences between the TM and the basilar membrane in Tecta ${ }^{\mathrm{C} 1509 \mathrm{G} / \mathrm{C} 1509 \mathrm{G}}$ mice are consistent with the TM being detached from the underlying epithelium in this mutant strain. However, because RL motion was similar in mice with either an attached or detached TM, we interpret these data to indicate that the radial tuning of the RL is not significantly imparted by the mechanical properties TM.

\section{Micromechanical interactions within the organ of Corti}

To better understand the basis of radial motion within the RL, we assessed the interactions between various subregions of the organ of Corti. We presented pure tone stimuli and measured vibratory responses from every voxel over the cross-section of the organ of Corti. As before, this measurement was performed at two different angles. Off-line, the images were segmented and the magnitudes and phases from each of 16 discrete locations were determined (Fig. 9A-C). We then calculated the 2-D motion pattern of each location. Within each image, vibratory phases at every location were referenced to the phase of the center of the basilar membrane, which was set to $0^{\circ}$, and we averaged the responses from 5-7 mice. Images demonstrating the motion over one sound cycle were created, by creating circles to plot the 2-D vibration magnitude, and coloring the circle to represent phase (Fig. 9D-J). We scaled the magnitudes of all locations within each image equally to make the motion easy to visualize. To aid with interpretation, movies were also created to show the motion (Movie 1).

In both live and dead CBA/CaJ mice, the predominant vector of motion at $5 \mathrm{kHz}$ for most locations was in the transverse direction (Fig. 9D, $G$ ). The entire organ of Corti vibrated nearly in phase, and there was little suggestion of changes in OHC length as might be expected if electromotility were occurring. However at $10 \mathrm{kHz}$, a larger component of radial motion was found in the structures above the basilar membrane in (Fig. 9E,F). At $20 \mathrm{~dB}$ SPL, when cochlear amplification is large relative to the passive motion of the organ of Corti, features suggestive of OHC electromotility were obvious (compare the motion patterns at the apical and basal ends of the OHC region in Fig. 9F).

In dead $\mathrm{CBA} / \mathrm{CaJ}$ mice, we could not study responses at 10 $\mathrm{kHz}$ because the vibratory magnitude for many voxels in the 

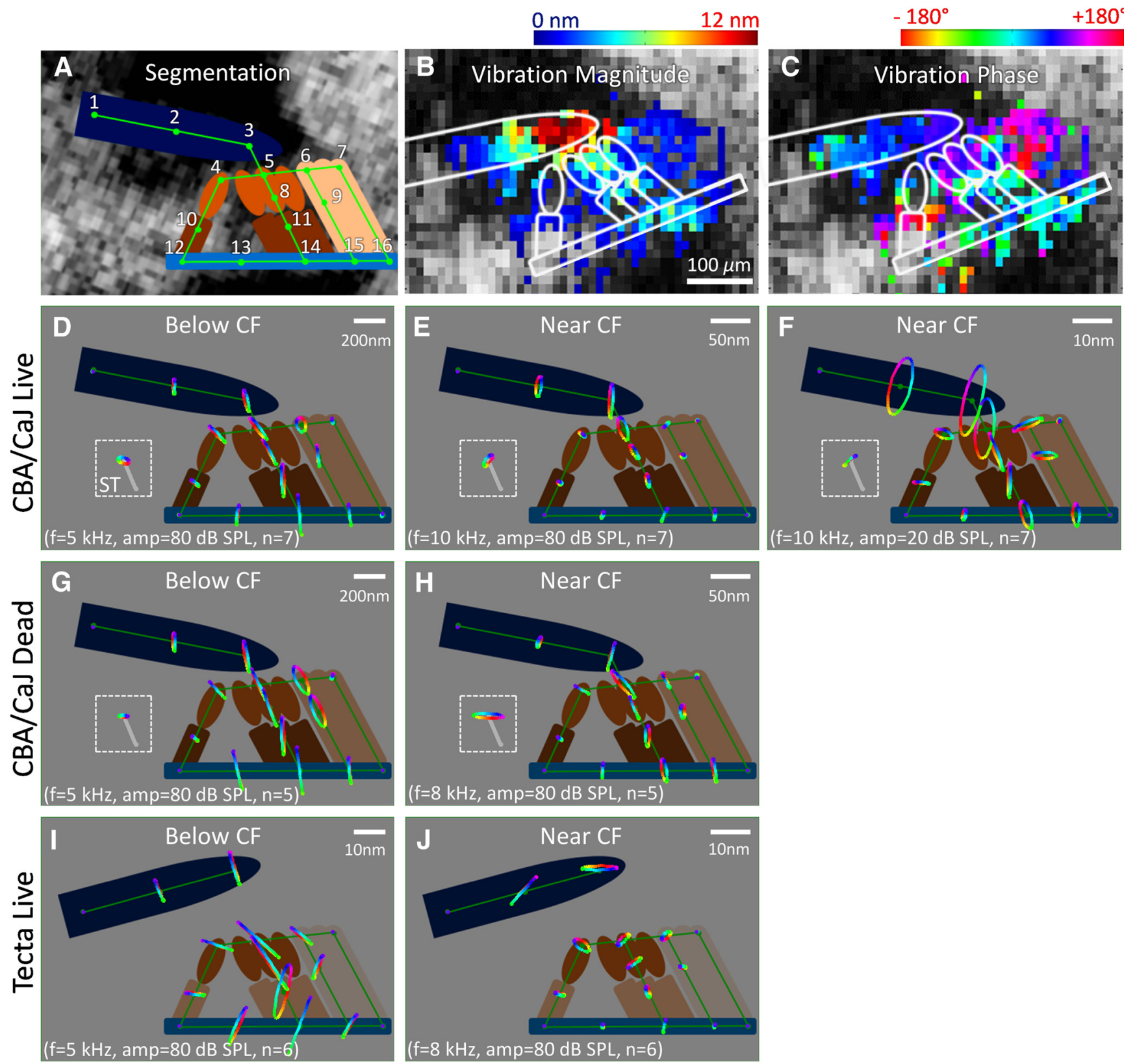

Figure 9. 2-D motion of the organ of Corti. $A$, We quantified vibration at 16 different measurement points. These points were chosen to correspond with the segmentation pattern shown superimposed on an anatomic $0 \mathrm{CT}$ image. $B, C$, A representative example of the vibration magnitude and phase responses to a $10 \mathrm{kHz}, 10 \mathrm{dBSPL}$ sound stimulus measured at one angle. The vibratory responses were pseudocolored on the corresponding anatomic image, and the segmentation model was overlaid. $\boldsymbol{D}-J$, Reconstructed 2-D motions at the 16 measurement points measured under different conditions. Each image represents average data from 5-7 mice. Data from live CBA/CaJ (D-F), dead CBA/CaJ $(\mathbf{G}, \boldsymbol{H})$, and Tecta ${ }^{\text {C15096/C15096 }}(\boldsymbol{I}, \boldsymbol{J})$ mice are shown. Left column, Data collected at a stimulus frequency below the $\mathrm{CF}(5 \mathrm{kHz})$. Middle and right columns, Near the $\mathrm{CF}(8-10 \mathrm{kHz})$. Tracing pattern at each point represents the vibration shape. Color gradient represents the vibration phase. Inset, 2-D motion of tip of the stereocilia relative to its root. The displacement tracings are magnified to permit clear visualization. Scale bars reflect the vibratory magnitude, not image size.

image were below the noise floor due to the fall off in the traveling wave without amplification. Therefore, we used $8 \mathrm{kHz}$ stimuli to achieve a compromise between being close to the CF and being able to record vibratory responses. At $8 \mathrm{kHz}$, radial movements of the TM and RL were antiphasic and enhanced the deflection of the OHC stereocilia (Fig. $9 \mathrm{H}$ ), although this was not seen at $5 \mathrm{kHz}$ (Fig. 9G). Using the same stimulus presentation strategy in live Tecta ${ }^{\mathrm{C} 1509 \mathrm{G} / \mathrm{C} 1509 \mathrm{G}}$ mice, the frequency dependence of the response was dramatic (Fig. 9I,J). All locations vibrated transversely in phase at $5 \mathrm{kHz}$, but there was dramatic antiphasic $\mathrm{RL}_{\mathrm{R}}$ and TM at $8 \mathrm{kHz}$. These 2-D vibratory data demonstrate that, below the CF, the pattern of motion of all structures is transverse and nearly in-phase. However, near the CF, the vibratory pattern becomes more complex, and this involves the emergence of radial motion within the hair cell epithelium and TM.

\section{Discussion}

OHCs produce cochlear amplification by selectively providing mechanical gain to achieve the wide dynamic range and exquisite frequency selectivity that distinguish mammalian hearing from that of all other animals (Manley, 2000; Ashmore, 2008; Dallos, 


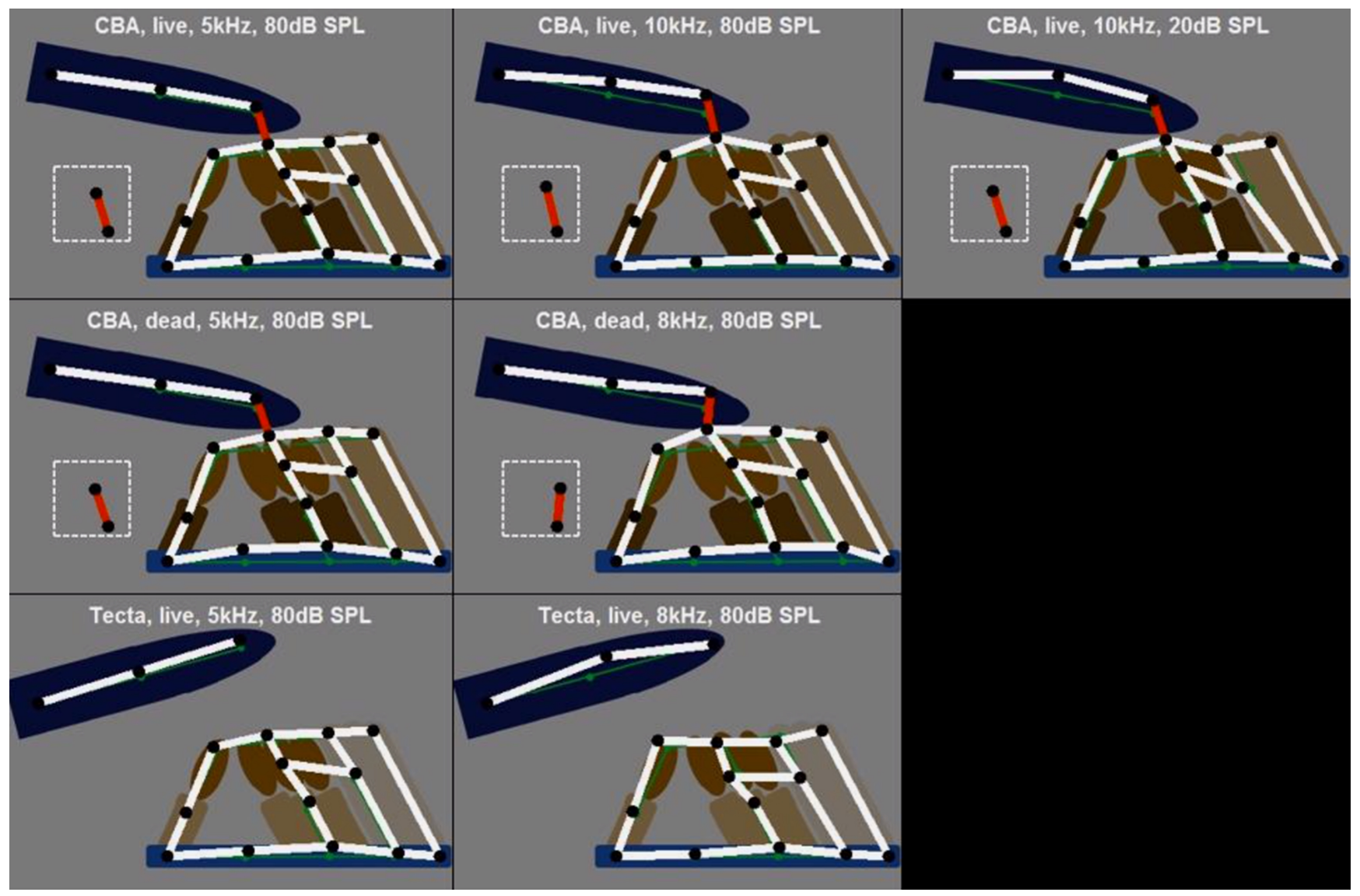

Movie 1. Two-dimensional motion of the organ of Corti. This movie is an animation of the data contained in Figure 9. Left column, Data collected at a stimulus frequency below the $\mathrm{CF}(5 \mathrm{kHz})$. Middle and right columns, Near the $\mathrm{CF}(8-10 \mathrm{kHz})$. Sound stimulus is at $5 \mathrm{kHz}$ and $80 \mathrm{dBSPL}, 10 \mathrm{kHz}$ and $80 \mathrm{dBSPL}$, and $10 \mathrm{kHz}$ and $20 \mathrm{dBSPL}$ in CBA/CaJ live mice for the first row, $5 \mathrm{kHz}$ and $80 \mathrm{~dB}$ SPL and $8 \mathrm{kHz}$ and $80 \mathrm{~dB} \mathrm{SPL}$ in CBA/CaJ dead mice for the second row, and $5 \mathrm{kHz}$ and $80 \mathrm{~dB}$ SPL and $8 \mathrm{kHz}$ and $80 \mathrm{~dB}$ SPL in Tecta live mice for the third row. Inset, 2-D motion of tip of the stereocilia relative to its root.

2008). All previous in vivo studies of cochlear mechanics have been made by measuring vibrations in the transverse direction, typically from the basilar membrane. However, hair cell stereocilia are oriented to be stimulated in response to radial forces. Here we show that radial motion within the organ of Corti is tuned to the frequency where cochlear amplification occurs rather than the frequency to which the underlying BM is tuned. The radial tuning of the RL and TM is measurable both in a dead cochlea where OHCs do not produce force and in Tecta mutants where $\mathrm{OHC}$ stereocilia are not stimulated, indicating that radial tuning derives from passive mechanical properties. Because radial tuning peaks at the characteristic frequency, these data suggest that radial tuning of the RL and TM produce selective stimulation of OHCs and thus might be, at least in part, responsible for tuning cochlear amplification to achieve sharp frequency selectivity (Fig. 10A).

Because of the potential for variations in our measurements due to technical limitations, the actual vibratory displacements of the structures may be different from what we measured. This is particularly relevant for our estimates of $\mathrm{OHC}$ stereociliary bundle deflection because we cannot directly visualize the stereociliary bundles with VOCTV. We estimated the potential for errors by assuming a tilted imaging angle of $\pm 10^{\circ}$ longitudinally (producing $1.5 \%$ variation in all displacement data), a variation of orientation angle of stereociliary bundles of $\pm 10^{\circ}$ with respect to the transverse axis we defined (producing a $1.5 \%$ variation in stereociliary displacement), or a variation of stereociliary length of $\pm 0.25 \mu \mathrm{m}$ (producing a $20 \%-30 \%$ variation in stereociliary angular deflection). Thus, together, our estimates of stereociliary bundle displacement could be off by as much as $3 \%$ and our estimates of stereociliary angular deflection could be off by as much as $35 \%$.

Nevertheless, our data provide reasonable estimates of $\mathrm{OHC}$ stereociliary bundle deflections under normal listening conditions in vivo; and more importantly, they support the conclusion of passive filtering due to radial motion, regardless of the accuracy of the deflection magnitude estimates. For every $1 \mathrm{~nm}$ of BM displacement, bundle deflection is $\sim 0.1-0.2 \mathrm{~nm}\left(0.01^{\circ}\right)$ when the stimulus frequency is below the CF and $5-8 \mathrm{~nm}\left(0.3^{\circ}-0.5^{\circ}\right)$ when the stimulus frequency is at the CF. Furthermore, the maximum bundle deflection to a relatively loud stimulus ( $80 \mathrm{~dB}$ SPL) is $\sim 150 \mathrm{~nm}\left(8.5^{\circ}\right)$ below $\mathrm{CF}$ and $\sim 50 \mathrm{~nm}\left(2.9^{\circ}\right)$ at CF. In dead mice, we estimate that the maximum bundle deflection to a relatively loud stimulus ( $80 \mathrm{~dB}$ SPL) at $5 \mathrm{kHz}$, where $\mathrm{BM}$ vibratory response peaks, is $\sim 30 \mathrm{~nm}\left(1.7^{\circ}\right)$. This corresponds to a bundle deflection of $0.12\left(0.01^{\circ}\right)$ for every $1 \mathrm{~nm}$ of BM displacement, which is similar to that found in the live mouse below CF.

Our estimates of stereociliary bundle motion in the dead mouse and the live mouse below CF, which predominantly reflects passive mechanics with little contribution of cochlear 

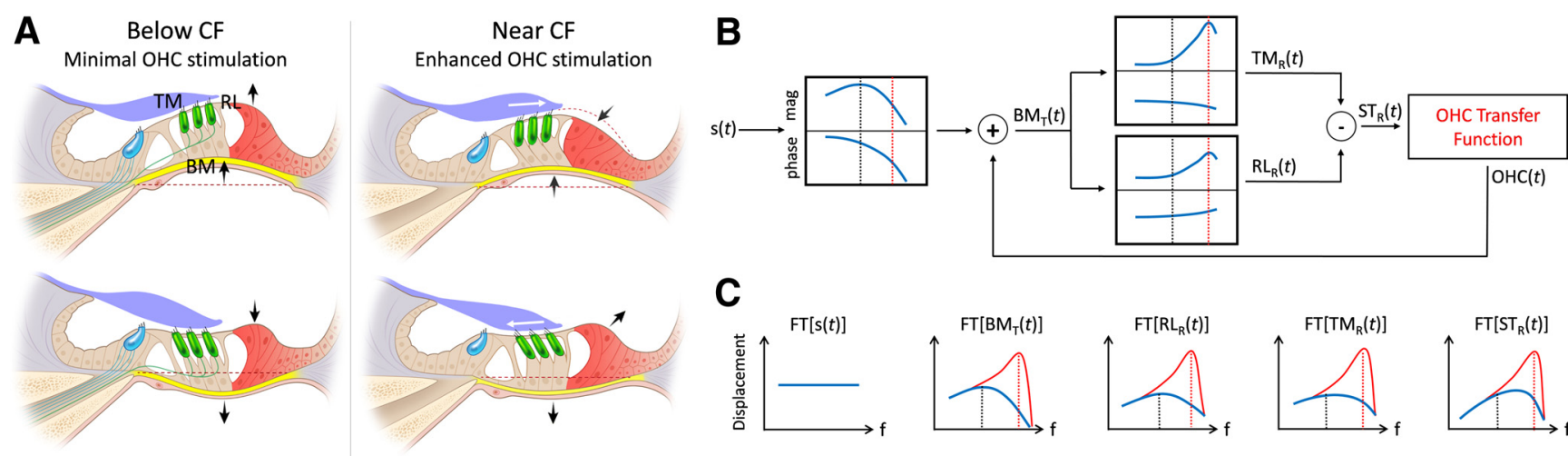

Figure 10. A, Summary of the micro-mechanical motion within the organ of Corti below and near the CF. Motion is predominantly transverse and in phase below CF, whereas more complex motion, including radial movement of the hair cell epithelium, occurs near CF. $\boldsymbol{B}$, A hypothetical system diagram of cochlear amplification. Bode plots provide a schematized form of the transfer functions that filter the response between the sites where we made vibratory measurements. The input sound pressure, $(s(t))$, is initially filtered to create a traveling wave with broad cochlear tuning when measured at the BM. Additional filtering within the organ of Corti creates radial responses within the TM and RL, which are more sharply tuned and antiphasic at the characteristic frequency. The difference between these responses creates $\mathrm{ST}_{\mathrm{R}}$. The complex $\mathrm{OHC}$ transfer function, which we did not measure, converts this into force, which then drives BM motion through a positive feedback loop. C, Schematized Fourier Transforms (FT) of the various vibratory responses at the various points in the system diagram for live (red) and dead (blue) mice.

amplification, agree with previous reports, although the experimental conditions were quite different. This includes modeling predictions (Neely and Kim, 1986; Steele et al., 2009; Nam et al., 2015), ex vivo hair cell patch-clamp studies of transduction (Ricci et al., 2005; Stauffer and Holt, 2007), and in vitro preparations (Chan and Hudspeth, 2005; Fridberger et al., 2006). For example, transduction currents measured in single OHCs demonstrate that $90 \%$ of the conductance occurs with a $151 \mathrm{~nm}\left(2.0^{\circ}\right)$ deflection (Géléoc et al., 1997). Although this measurement was not done at acoustic frequencies, it still corresponds well with our bundle deflection estimates to 80 dB SPL stimuli. Similarly measurements in the gerbil hemicochlea demonstrate that the angular deflection of OHC stereociliary bundle corresponding to a $10 \%-90 \%$ activation of transducer conductance is $1.9^{\circ}-2.1^{\circ}$ and the OHC bundle deflection is $0.01^{\circ}-0.04^{\circ}$ per $\mathrm{nm}$ of $\mathrm{BM}$ displacement (He et al., 2004). Our angular deflection estimate for stimuli below the $\mathrm{CF}$ also agrees with this measurement nicely.

Our data demonstrate that, in a purely passive condition, OHCs are stimulated over a relatively broad frequency range. However, relative to the basilar membrane motion, they are sharply tuned to be stimulated more near the CF. This finding is important because, in live mice, the positive feedback provided by OHC force production (Guinan et al., 2012) is likely to further enhance OHC stimulation at the CF. Our hypothetical model of the impact of this frequency response is shown in Figure $10 B, C$. Although there is evidence of a low level of cochlear gain below CF when measured at the RL and TM, this does not significantly impact the BM response. Only when the radial motion of the organ of Corti enhances OHC stimulation does amplification becomes maximal. This is consistent with several models of cochlear amplification (Shera, 2007; de Boer et al., 2007), as well as the limited in vivo experimental data that are available (Nilsen and Russell, 2000; Chen et al., 2011; Fisher et al., 2012; Ramamoorthy et al., 2014) and ex vivo (Hu et al., 1999; Cai et al., 2003; Karavitaki and Mountain, 2007b). In particular, our data strongly support previously published data showing that targeted photo inactivation of prestin well to the base of the CF does not alter cochlear gain, whereas inactivation of prestin just basal to the peak of the CF significantly reduces gain (Fisher et al., 2012). Furthermore, our data extend this finding by suggesting that the mechanism why the local activation of prestin-based electromotility tunes cochlear amplification is because the passive tuning of the radial motion of the hair cell epithelium begins to promote $\mathrm{OHC}$ stimulation and increase positive feedback just below CF.

The findings in Tecta ${ }^{\mathrm{C} 1509 \mathrm{G} / \mathrm{C} 1509 \mathrm{G}}$ mice suggest that the source of the additional filtering that tunes OHC stereociliary stimulation, at least in part, derives from within the epithelium. It is unlikely to derive from processes associated with OHC electromotility, as electrical stimulation evokes broadband rather than tuned vibratory responses in isolated OHCs (Frank et al., 1999) and in Tecta ${ }^{\mathrm{C} 1509 \mathrm{G} / \mathrm{C} 1509 \mathrm{G}}$ mice (Ren et al., 2016). The mammalian cochlea evolved not only the specialized force-producing OHC, but also a highly structured framework of cells that sit on top of the basilar membrane (Manley, 2012). These cells (including Deiters', pillar, Hensen's, Boettcher's, and Claudius' cells) not only support and orient the hair cells, but also form a crosslinked, truss-like network both in the radial and longitudinal directions (Spicer and Schulte, 1994). It is possible that the passive mechanical properties of the supporting cells establish the frequency response of radial motion, and that these properties vary along the length of the cochlea in a tonotopic distribution.

Another source of additional filtering within the cochlea is likely to be the TM. Tuning in the radial direction has been identified within the excised TM (Ghaffari et al., 2007; Sellon et al., 2015). In mutant mice in which the TM is attached to the stereociliary bundles, but has abnormal mechanics, frequency tuning is altered (Russell et al., 2007; Ghaffari et al., 2010). Consistent with this, the data we show here demonstrate that the TM does not simply follow the movements of the underlying cochlear epithelium but instead has different frequency-dependent changes in its vibration patterns. Given that the TM is constructed by proteins secreted by the supporting cells during development of the organ of Corti, it is conceivable that both structures develop the mechanical properties that underlie their tuning in synchrony.

In conclusion, our data indicate that micromechanics within the mammalian cochlea are complex and involve a significant radial component that appears to be controlled by the passive mechanics of the organ of Corti. This radial tuning may play a role in determining which OHCs will be stimulated, thus tuning cochlear amplification at the selected cochlear location. Why might sharp frequency tuning have evolved to be controlled by a different mechanism than gain? Separating these features elimi- 
nates some of the downsides that would occur if a single active process provided both gain and tuning. The benefits of cochlear gain are that it improves the ability to hear quieter sounds and it extends the bandwidth of hearing to higher frequencies. However, without sharp frequency filtering before the amplification step, background noise would be increased together with the desired signal. Feedback would also be more of a problem. Indeed, both of these problems are the major concerns of patients who try hearing aids, which primarily provide gain (McCormack and Fortnum, 2013). Consequently, preamplification filtering is commonly used in hearing aid technology to reduce feedback and improve hearing in noisy background environments (Kates, 2005). Our data argue that there is sharp relative tuning within the passive organ of Corti that is unchanged in the active cochlea, and this relative tuning is part of the full picture of cochlear mechanics.

\section{Notes}

Supplemental material for this article is available at https://oghalailab. stanford.edu/. This includes a link to download the radial and transverse vibratory data. This material has not been peer reviewed.

\section{References}

Allen JB, Fahey PF (1992) Using acoustic distortion products to measure the cochlear amplifier gain on the basilar membrane. J Acoust Soc Am 92: 178-188. CrossRef Medline

Applegate BE, Shelton RL, Gao SS, Oghalai JS (2011) Imaging highfrequency periodic motion in the mouse ear with coherently interleaved optical coherence tomography. Opt Lett 36:4716-4718. CrossRef Medline

Ashmore J (2008) Cochlear outer hair cell motility. Physiol Rev 88:173-210. CrossRef Medline

Brownell WE, Bader CR, Bertrand D, de Ribaupierre Y (1985) Evoked mechanical responses of isolated cochlear outer hair cells. Science 227: 194-196. CrossRef Medline

Cai H, Richter CP, Chadwick RS (2003) Motion analysis in the hemicochlea. Biophys J 85:1929-1937. CrossRef Medline

Chan DK, Hudspeth AJ (2005) $\mathrm{Ca}^{2+}$ current-driven nonlinear amplification by the mamalian cochlea in vitro. Nat Neurosci 8:149-155. CrossRef Medline

Chen F, Zha D, Fridberger A, Zheng J, Choudhury N, Jacques SL, Wang RK, Shi X, Nuttall AL (2011) A differentially amplified motion in the ear for near-threshold sound detection. Nat Neurosci 14:770-774. CrossRef Medline

Dallos P (2008) Cochlear amplification, outer hair cells and prestin. Curr Opin Neurobiol 18:370-376. CrossRef Medline

Dallos P, Wu X, Cheatham MA, Gao J, Zheng J, Anderson CT, Jia S, Wang X, Cheng WH, Sengupta S, He DZ, Zuo J (2008) Prestin-based outer hair cell motility is necessary for mammalian cochlear amplification. Neuron 58:333-339. CrossRef Medline

Davis H (1983) An active process in cochlear mechanics. Hear Res 9:79-90. CrossRef Medline

de Boer E, Nuttall AL, Shera CA (2007) Wave propagation patterns in a "classical" three-dimensional model of the cochlea. J Acoust Soc Am 121: 352-362. CrossRef Medline

Dong W, Olson ES (2013) Detection of cochlear amplification and its activation. Biophys J 105:1067-1078. CrossRef Medline

Drenckhahn D, Kellner J, Mannherz HG, Gröschel-Stewart U, KendrickJones J, Scholey J (1982) Absence of myosin-like immunoreactivity in stereocilia of cochlear hair cells. Nature 300:531-532. CrossRef Medline

Ellerbee AK, Izatt JA (2007) Phase retrieval in low-coherence interferometric microscopy. Opt Lett 32:388-390. CrossRef Medline

Evans EF (1972) The frequency response and other properties of single fibres in the guinea-pig cochlear nerve. J Physiol 226:263-287. CrossRef Medline

Evans EF, Klinke R (1982) The effects of intracochlear and systemic furosemide on the properties of single cochlear nerve fibres in the cat. J Physiol 331:409-427. CrossRef Medline

Fettiplace R (2006) Active hair bundle movements in auditory hair cells. J Physiol 576:29-36. CrossRef Medline
Fisher JA, Nin F, Reichenbach T, Uthaiah RC, Hudspeth AJ (2012) The spatial pattern of cochlear amplification. Neuron 76:989-997. CrossRef Medline

Frank G, Hemmert W, Gummer AW (1999) Limiting dynamics of highfrequency electromechanical transduction of outer hair cells. Proc Natl Acad Sci U S A 96:4420-4425. CrossRef Medline

Fridberger A, Tomo I, Ulfendahl M, Boutet de Monvel J (2006) Imaging hair cell transduction at the speed of sound: dynamic behavior of mammalian stereocilia. Proc Natl Acad Sci U S A 103:1918-1923. CrossRef Medline

Furness DN, Mahendrasingam S, Ohashi M, Fettiplace R, Hackney CM (2008) The dimensions and composition of stereociliary rootlets in mammalian cochlear hair cells: comparison between high- and lowfrequency cells and evidence for a connection to the lateral membrane. J Neurosci 28:6342-6353. CrossRef Medline

Gao SS, Raphael PD, Wang R, Park J, Xia A, Applegate BE, Oghalai JS (2013) In vivo vibrometry inside the apex of the mouse cochlea using spectral domain optical coherence tomography. Biomed Opt Express 4:230-240. CrossRef Medline

Gao SS, Wang R, Raphael PD, Moayedi Y, Groves AK, Zuo J, Applegate BE, Oghalai JS (2014) Vibration of the organ of Corti within the cochlear apex in mice. J Neurophysiol 112:1192-1204. CrossRef Medline

Geisler CD, Sang C (1995) A cochlear model using feed-forward outer-haircell forces. Hear Res 86:132-146. CrossRef Medline

Géléoc GS, Lennan GW, Richardson GP, Kros CJ, Géléoc GS, Euge P, Géléoc GS, Lennan GW, Richardson GP, Kros CJ (1997) A quantitative comparison of mechanoelectrical transduction in vestibular and auditory hair cells of neonatal mice. Proc Biol Sci 264:611-621. CrossRef Medline

Ghaffari R, Aranyosi AJ, Freeman DM (2007) Longitudinally propagating traveling waves of the mammalian tectorial membrane. Proc Natl Acad Sci U S A 104:16510-16515. CrossRef Medline

Ghaffari R, Aranyosi AJ, Richardson GP, Freeman DM (2010) Tectorial membrane travelling waves underlie abnormal hearing in Tectb mutant mice. Nat Commun 1:96. CrossRef Medline

Gu JW, Hemmert W, Freeman DM, Aranyosi AJ (2008) Frequencydependent shear impedance of the tectorial membrane. Biophys J 95: 2529-2538. CrossRef Medline

Guinan JJ Jr, Salt A, Cheatham MA (2012) Progress in cochlear physiology after Békésy. Hear Res 293:12-20. CrossRef Medline

Gummer AW, Hemmert W, Zenner HP (1996) Resonant tectorial membrane motion in the inner ear: its crucial role in frequency tuning. Proc Natl Acad Sci U S A 93:8727-8732. CrossRef Medline

Hakizimana P, Brownell WE, Jacob S, Fridberger A (2012) Sound-induced length changes in outer hair cell stereocilia. Nat Commun 3:1094. CrossRef Medline

He DZ, Jia S, Dallos P (2004) Mechanoelectrical transduction of adult outer hair cells studied in a gerbil hemicochlea. Nature 429:766-770. CrossRef Medline

Hu X, Evans BN, Dallos P (1999) Direct visualization of organ of corti kinematics in a hemicochlea. J Neurophysiol 82:2798-2807. Medline

Hubbard A (1993) A traveling-wave amplifier model of the cochlea. Science 259:68-71. CrossRef Medline

Hudspeth AJ (2014) Integrating the active process of hair cells with cochlear function. Nat Rev Neurosci 15:600-614. CrossRef Medline

Karavitaki KD, Mountain DC (2007a) Evidence for outer hair cell driven oscillatory fluid flow in the tunnel of Corti. Biophys J 92:3284-3293. CrossRef Medline

Karavitaki KD, Mountain DC (2007b) Imaging electrically evoked micromechanical motion within the organ of Corti of the excised gerbil cochlea. Biophys J 92:3294-3316. CrossRef Medline

Kates JM (2005) Principles of digital dynamic-range compression. Trends Amplif 9:45-76. CrossRef Medline

Lee HY, Raphael PD, Park J, Ellerbee AK, Applegate BE, Oghalai JS (2015) Noninvasive in vivo imaging reveals differences between tectorial membrane and basilar membrane traveling waves in the mouse cochlea. Proc Natl Acad Sci U S A 112:3128-3133. CrossRef Medline

Legan PK, Lukashkina VA, Goodyear RJ, Kössi M, Russell IJ, Richardson GP (2000) A targeted deletion in alpha-tectorin reveals that the tectorial membrane is required for the gain and timing of cochlear feedback. Neuron 28:273-285. CrossRef Medline

Lelli A, Asai Y, Forge A, Holt JR, Géléoc GS (2009) Tonotopic gradient in the 
developmental acquisition of sensory transduction in outer hair cells of the mouse cochlea. J Neurophysiol 101:2961-2973. CrossRef Medline

Liu CC, Gao SS, Yuan T, Steele C, Puria S, Oghalai JS (2011) Biophysical mechanisms underlying outer hair cell loss associated with a shortened tectorial membrane. J Assoc Res Otolaryngol 12:577-594. CrossRef Medline

Manley GA (2000) Cochlear mechanisms from a phylogenetic viewpoint. Proc Natl Acad Sci U S A 97:11736-11743. CrossRef Medline

Manley GA (2012) Evolutionary paths to mammalian cochleae. J Assoc Res Otolaryngol 13:733-743. CrossRef Medline

Markin VS, Hudspeth AJ (1995) Modeling the active process of the cochlea: phase relations, amplification, and spontaneous oscillation. Biophys J 69:138-147. CrossRef Medline

McCormack A, Fortnum H (2013) Why do people fitted with hearing aids not wear them? Int J Audiol 52:360-368. CrossRef Medline

Mountain DC, Hubbard AE (1994) A piezoelectric model of outer hair cell function. J Acoust Soc Am 95:350-354. CrossRef Medline

Nam JH, Peng AW, Ricci AJ (2015) Underestimated sensitivity of mammalian cochlear hair cells due to splay between stereociliary columns. Biophys J 108:2633-2647. CrossRef Medline

Narayanan P, Chatterton P, Ikeda A, Ikeda S, Corey DP, Ervasti JM, Perrin BJ (2015) Length regulation of mechanosensitive stereocilia depends on very slow actin dynamics and filament severing proteins. Nat Commun 6:554-561. CrossRef Medline

Neely ST, Kim DO (1986) A model for active elements in cochlear biomechanics. J Acoust Soc Am 79:1472-1480. CrossRef Medline

Nilsen KE, Russell IJ (2000) The spatial and temporal representation of a tone on the guinea pig basilar membrane. Proc Natl Acad Sci U S A 97: 11751-11758. CrossRef Medline

Nin F, Reichenbach T, Fisher JA, Hudspeth AJ (2012) Contribution of active hair-bundle motility to nonlinear amplification in the mammalian cochlea. Proc Natl Acad Sci U S A 109:21076-21080. CrossRef Medline

Nowotny M, Gummer AW (2011) Vibration responses of the organ of Corti and the tectorial membrane to electrical stimulation. J Acoust Soc Am 130:3852-3872. CrossRef Medline

Nuttall AL, Dolan DF (1996) Steady-state sinusoidal velocity responses of the basilar membrane in guinea pig. J Acoust Soc Am 99:1556-1565. CrossRef Medline

Oghalai JS (2004) Chlorpromazine inhibits cochlear function in guinea pigs. Hear Res 198:59-68. CrossRef Medline

Peng AW, Ricci AJ (2011) Somatic motility and hair bundle mechanics, are both necessary for cochlear amplification? Hear Res 273:109-122. CrossRef Medline

Ramamoorthy S, Zha D, Chen F, Jacques SL, Wang R, Choudhury N, Nuttall AL, Fridberger A (2014) Filtering of acoustic signals within the hearing organ. J Neurosci 34:9051-9058. CrossRef Medline

Ren T, He W, Barr-Gillespie PG (2016) Reverse transduction measured in the living cochlea by low-coherence heterodyne interferometry. Nat Commun 7:10282. CrossRef Medline

Rhode WS (1971) Observations of the vibration of the basilar membrane in squirrel monkeys using the Mossbauer technique. J Acoust Soc Am 49 [Suppl 2]:1218.

Ricci AJ, Kennedy HJ, Crawford AC, Fettiplace R (2005) The transduction channel filter in auditory hair cells. J Neurosci 25:7831-7839. CrossRef Medline

Robles L, Ruggero MA (2001) Mechanics of the mammalian cochlea. Physiol Rev 81:1305-1352. Medline

Ruggero MA, Rich NC (1991) Furosemide alters organ of Corti mechanics: evidence for feedback of outer hair cells upon the basilar membrane. J Neurosci 11:1057-1067. Medline

Russell IJ, Legan PK, Lukashkina VA, Lukashkin AN, Goodyear RJ, Richardson GP (2007) Sharpened cochlear tuning in a mouse with a genetically modified tectorial membrane. Nat Neurosci 10:215-223. CrossRef Medline

Sellon JB, Farrahi S, Ghaffari R, Freeman DM (2015) Longitudinal spread of mechanical excitation through tectorial membrane traveling waves. Proc Natl Acad Sci U S A 112:12968-12973. CrossRef Medline

Shera CA (2007) Laser amplification with a twist: traveling-wave propagation and gain functions from throughout the cochlea. J Acoust Soc Am 122:2738-2758. CrossRef Medline

Song L, Santos-Sacchi J (2013) Disparities in voltage-sensor charge and electromotility imply slow chloride-driven state transitions in the solute carrier SLC26a5. Proc Natl Acad Sci U S A 110:3883-3888. CrossRef Medline

Soons JA, Ricci AJ, Steele CR, Puria S (2015) Cytoarchitecture of the mouse organ of Corti from base to apex, determined using in situ two-photon imaging. J Assoc Res Otolaryngol 16:47-66. CrossRef Medline

Spicer SS, Schulte BA (1994) Differences along the place-frequency map in the structure of supporting cells in the gerbil cochlea. Hear Res 79: 161-177. CrossRef Medline

Stauffer EA, Holt JR (2007) Sensory transduction and adaptation in inner and outer hair cells of the mouse auditory system. J Neurophysiol 98: 3360-3369. CrossRef Medline

Steele CR, Monvel J de, Puria S, Boutet de Monvel J, Puria S, de Monvel J (2009) A multiscale model of the organ of Corti. J Mech 4:755-778.

Tilney LG, Derosier DJ, Mulroy MJ (1980) The organization of actin filaments in the stereocilia of cochlear hair cells. J Cell Biol 86:244-259. CrossRef Medline

von Békésy G (1960) Experiments in hearing. New York: McGraw-Hill.

Weitzel EK, Tasker R, Brownell WE (2003) Outer hair cell piezoelectricity: frequency response enhancement and resonance behavior. J Acoust Soc Am 114:1462-1466. CrossRef Medline

Xia A, Visosky AM, Cho JH, Tsai MJ, Pereira FA, Oghalai JS (2007) Altered traveling wave propagation and reduced endocochlear potential associated with cochlear dysplasia in the BETA2/NeuroD1 null mouse. J Assoc Res Otolaryngol 8:447-463. CrossRef Medline

Xia A, Gao SS, Yuan T, Osborn A, Bress A, Pfister M, Maricich SM, Pereira FA, Oghalai JS (2010) Deficient forward transduction and enhanced reverse transduction in the alpha tectorin C1509G human hearing loss mutation. Dis Model Mech 3:209-223. CrossRef Medline

Xia A, Song Y, Wang R, Gao SS, Clifton W, Raphael P, Chao SI, Pereira FA, Groves AK, Oghalai JS (2013) Prestin regulation and function in residual outer hair cells after noise-induced hearing loss. PLoS One 8:e82602. CrossRef Medline

Yoon YJ, Steele CR, Puria S (2011) Feed-forward and feed-backward amplification model from cochlear cytoarchitecture: an interspecies comparison. Biophys J 100:1-10. CrossRef Medline 